\title{
Research on Peak Shear Strength Criterion of Rock Joints Based on the Evolution of Dilation Angle
}

Linnan Ding ( $\square$ LinnanDing@163.com )

Nanjing Hydraulic Research Institute

\section{Guoying Li}

Nanjing Hydraulic Research Institute

\section{Research Article}

Keywords: Rock mechanics, joint, peak shear strength, three-dimensional morphology parameter

Posted Date: March 6th, 2021

DOl: https://doi.org/10.21203/rs.3.rs-287610/v1

License: (c) (i) This work is licensed under a Creative Commons Attribution 4.0 International License. Read Full License

Version of Record: A version of this preprint was published at Geotechnical and Geological Engineering on April 16th, 2021. See the published version at https://doi.org/10.1007/s10706-021-01801-3. 


\title{
Research on peak shear strength criterion of rock joints based on the \\ evolution of dilation angle
}

\author{
Linnan Ding ${ }^{1,2}$, Guoying $\mathrm{Li}^{1,2}$ \\ (1. Geotechnical Engineering Dept, Nanjing Hydraulic Research Institute, Nanjing 210024, China; 2. Key Laboratory of Failure \\ Mechanism and Safety Control Techniques of Earth-Rock Dam of the Ministry of Water Resources, Nanjing 210029, China)
}

\begin{abstract}
The surface morphology of joints directly determines the contact area and peak shear strength of rock in shearing. This research gives a detailed description of the three-dimensional roughness parameters proposed by Grasselli, and discusses the morphology characteristics of the roughness parameter $C$ in different ranges. Quoting Xia's direct shear test data, the relationship of peak shear strength, peak shear strength/normal stress, residual strength, dilation with roughness and normal stress are studied. The deficiencies in the previous classical criteria are explained in detail. A new peak shear strength criterion is established based on the boundary conditions of the dilation angle. The nonlinear characteristic of peak shear strength is included in the peak dilation angel, so that the new criterion satisfies the Mohr-Coulomb law of nonlinear form. In the expression of the initial dilation angle, the new criterion satisfies the fact that the peak shear strength decreases after once sheared. Finally, the test data of Grasselli and Yang are used to compare the prediction accuracy of Grasselli's criterion, Yang's criterion, Xia's criterion and the new criterion. In general, the new criterion has the highest degree of agreement with the test results.
\end{abstract}

Keywords: Rock mechanics; joint; peak shear strength; three-dimensional morphology parameter Symbols

$\theta^{*} \quad$ Apparent dip angle $\left({ }^{\circ}\right)$

$\alpha \quad$ Azimuth angle $\left({ }^{\circ}\right)$

$\theta_{\text {cr }}{ }^{*} \quad$ Threshold apparent dip angle $\left(^{\circ}\right)$

$A_{\theta^{*}} \quad$ Total potential contact area

$C$ Roughness parameter defined by

Grasselli

$\theta_{\max }{ }^{*} \quad$ Maximum apparent dip angle $\left(^{\circ}\right)$

$A_{0} \quad$ Maximum contact area

$\sigma_{\mathrm{n}} \quad$ Normal stress (MPa)

$\sigma_{\mathrm{c}} \quad$ Uniaxial compressive strength (MPa)

$\sigma_{\mathrm{t}} \quad$ Uniaxial tensile strength (MPa)

$\varphi_{\mathrm{b}} \quad$ Basic friction angle $\left(^{\circ}\right)$

$\varphi_{\mathrm{r}}{ }^{*} \quad$ Residual friction angle $\left(^{\circ}\right)$

$i_{\mathrm{p}} \quad$ Peak dilation angle $\left({ }^{\circ}\right)$

$i_{0} \quad$ Initial dilation angle $\left({ }^{\circ}\right)$

$K \quad$ Attenuation correction coefficient

$\beta \quad$ Angle between schistosity plane and plane normal to the joint $\left({ }^{\circ}\right)$

$\tau_{\mathrm{p}} \quad$ Peak shear strength (MPa)

$\tau_{\text {residual }} \quad$ Residual strength (MPa)

$\tau_{\mathrm{m}} \quad$ Measured peak shear strength (MPa) 
$\tau_{\mathrm{c}} \quad$ Calculated peak shear strength by the

criterion (MPa)

$\delta_{\text {avg }}$ Average relative error

$\mu \quad$ Standard deviation of the relative error

\section{Introduction}

In rock mechanics, the existence of joints destroys the integrity of rock and softens its shear strength. In actual engineering problems, rock mass exhibits two mechanical behaviors in shearing according to different types of normal stress. Such as the sliding of rock mass on a slope, the normal stress on rock mass is a constant normal load (CNL), and its normal displacement can expand freely in shearing. In the foundation engineering of dam, the normal displacement of rock mass will be restricted and maintain a constant value in shearing, which belongs to constant normal stiffness (CNS). Grasselli (2003) believes that there is no dilation before the peak shear strength, and the two conditions (CNL, CNS) have the same mechanical properties. After the peak shear strength, the limited dilation under the CNS condition will causes an increase in normal stress. The test equipment already has test environment for CNS condition, but the continuous change of normal stress is not conducive to establishing an accurate peak shear strength criterion. Therefore, existing tests are mainly focused on CNL condition.

For the study of peak shear strength, Patton (1966) proposed a bilinear criterion that satisfies the Mohr-Coulomb law on the basis of saw-tooth tests. Ladanyi and Archambault (1969) put forward the concept of shear area ratio $\left(\alpha_{\mathrm{s}}\right)$, and developed a criterion that capture the key characteristics of shear resistance, i.e., shear-off, dilation and basic friction. Barton and Choubey (1977) conducted direct shear tests on 136 groups of natural rock joints, and defined the joint roughness coefficient (JRC). According to different results, 10 standard profiles were defined. Barton and Choubey (1977) considered the influence of joint compressive strength (JCS) and JRC on peak dilation angle, and proposed the JRC-JCS model. Many scholars (Zhao 1997, Johansson 2014, Tang 2016) used the joint matching coefficient (JMC) to describe the coupling degree of the upper and lower joints, and proposed the corresponding criterion.

Although JRC was suggested as a useful index for describing joint roughness by the International Society for Rock Mechanics (ISRM 1978) and widely used in engineering practice, it is too subjective to obtain JRC through visual comparison and calculated by back analysis (Zheng 2016). Some scholars (Jang 2014, Li 2015) used the fractal dimension method to quantitatively analyze JRC. Several scholars also calculated JRC through the statistical method, which mainly focus on the single parameters $Z_{2}$ (the root mean square of the first deviation of the profile) (Jang 2014, Yang 2001, Tatone 2010, Li 2015) and $R_{\mathrm{p}}$ (the ratio of the true length of joint to its projected length in the joint plane) (Jang 2014, Yang 2001, Tatone 2010, Li 2015). Zhang (2016) and Liu (2017) simultaneously introduced two parameters for statistical analysis, and both achieved high accuracy.

Most of above studies were based on the two-dimensional morphology of joints, which cannot fully reflect the overall morphology of the actual joint surface. Belem (2000) studied the roughness under three-dimensional morphology from the aspects of slope, height, curvature and anisotropy, and proposed an empirical criterion for peak shear strength. Grasselli (2003) introduced the maximum apparent dip angle $\left(\theta_{\max }{ }^{*}\right)$, the maximum potential contact area $\left(A_{0}\right)$ and the roughness parameter $(C)$ to express the change of potential contact area $\left(A_{\theta^{*}}\right)$ in a specific shear direction, and established the corresponding peak shear strength criterion. Tatone (2010) 
discussed the Grasselli's parameters in the two-dimensional situation, using $\theta_{\max }^{*} /(C+1)_{2 \mathrm{D}}$ to represent the joint roughness and reconstructing 10 standard profiles to obtain the conversion between $\theta_{\max }{ }^{*} /(C+1)_{2 \mathrm{D}}$ and JRC. The criterion of Grasselli has high accuracy, but its form does not satisfies the Mohr-Coulomb law and cannot reflect the evolution of the dilation angle. Xia (2014) introduced the average apparent dip angle $\left(\theta_{\text {avg }}\right)$ into the criterion of Grasselli. Although Xia's criterion satisfies the Mohr-Coulomb law, the evolution of the dilation angle with the normal stress is inconsistent with reality. Yang (2016) established a new criterion based on the evolution characteristics of Schneider's dilation angle, but its criterion cannot reflects the saw-tooth joint and does not considers the influence of maximum potential contact area.

Several scholars have modified the morphological parameters of Grasselli. Liu $(2017,2018)$ proposed the concept of initial contact area ratio $A_{\theta^{*}}{ }^{+}=\exp \left(-\left(\theta^{*} / \bar{\theta}^{*}\right)^{n}\right)$, and used the characteristic angle $\left(\bar{\theta}^{*}\right)$, fitting parameter $(n)$, and average joint height $(h)$ to represent the morphology of joint. The criterion proposed by Liu can simultaneously calculate the peak shear strength in 2D and 3D. Tian (2018) developed a morphological parameter $\left(C^{\prime}\right)$ based on the roughness $(C)$. Ma (2020) proposed the concept of resistance angle $(\omega)$, which can quantitatively express the range of the damage area. Ban $(2018,2020)$ developed a new roughness parameter (AHD) based on the roughness parameters of Grasselli, and obtained a new criterion. However, these roughness parameters are essentially the same as the Grasselli's roughness parameters, and the key is to establish the relationship between the peak shear strength and the contact area.

In this paper, the roughness parameter of Grasselli is extended, and a new criterion is established according to the boundary conditions of the dilation angle. New criterion satisfies the fact that peak shear strength decreases after first shear, and considers the contribution of the maximum potential contact area and schistosity structure to the peak shear strength.

\section{The New Peak Shear Strength Criterion}

\subsection{Surface Roughness Evaluation Methodology}

The contact area of rock joint in shearing directly determines the peak shear strength. However, by observing the sheared samples, it is found that the actual contact area is only a small part of the total area (Grasselli 2002). These randomly distributed contact area are difficult to express with a single profile. It is necessary to consider the overall morphology of the rock joint to understand the mechanism of roughness on peak shear strength. Through a large number of tests, Grasselli (2002) first found that the potential damaged areas in shearing appeared on the side facing the shear direction, and appeared first in the steeply inclined asperities.

Grasselli (2002) divided the joint surface into adjacent triangles, and the position of each triangle is identified by its dip angle $(\theta)$ and azimuth angle $(\alpha)$, as shown in Fig. 1. Dip angle $(\theta)$ is the angle between triangle surface and the shear plane. Azimuth angle $(\alpha)$ is the angle between the true dip vector $(d)$ projected on the shear plane $(w)$ and the shear vector $(t)$, which is measured clockwise from $t$. The apparent dip angle $\left(\theta^{*}\right)$ describes the contribution of each triangle inclination with respect to the chosen shear direction. The calculation equation of apparent dip angle $\left(\theta^{*}\right)$ was proposed by Grasselli (2002):

$$
\theta=\cos ^{-1}\left(\frac{d \cdot w}{|d| \cdot|w|}\right)
$$




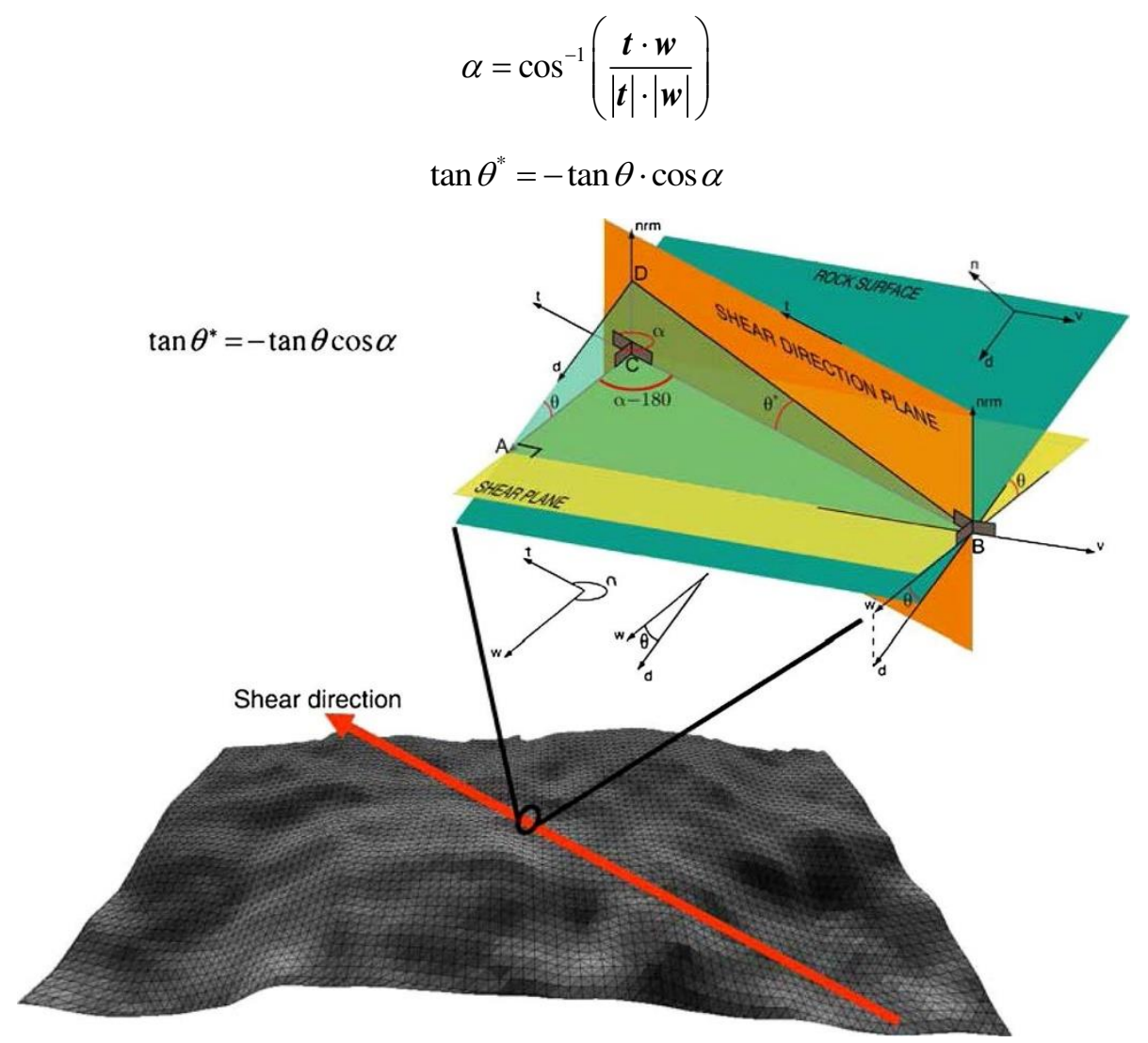

Fig. 1 Geometrical identification of the apparent dip angle $\theta^{*}$, measured along the shear direction (Grasselli 2002; Nasseri 2010; Xia 2014)

Not all apparent dip angle $\left(\theta^{*}\right)$ can produce shear resistance. There is a threshold apparent dip angle $\left(\theta_{\mathrm{cr}}^{*}\right)$, which is unique for each applied normal stress. The areas of the surface inclined exactly at $\theta_{\mathrm{cr}}{ }^{*}$ will be just in contact, whereas the areas inclined more than $\theta_{\mathrm{cr}}{ }^{*}$ will be deformed or crushed. The total areas inclined more than $\theta_{\text {cr }}{ }^{*}$ is defined as "total potential contact area $\left(A_{\theta^{*}}\right)$ ". Grasselli (2002) drew $A_{\theta^{*}}$ and several values of $\theta^{*}$ points on the $A_{\theta^{*}-} \theta^{*}$ plane, and found that their relationship satisfies the exponential form, as shown in Eq. 4. Moreover, the range of $A_{\theta^{*}}$ is between 0 and $A_{0}$, where $A_{0}$ is the maximum possible contact area in the shear direction. The range of $\theta^{*}$ is between 0 and $\theta_{\max }{ }^{*}$, where $\theta_{\max }{ }^{*}$ is the maximum apparent dip angle in the shear direction.

$$
A_{\theta^{*}}=A_{0}\left(\frac{\theta_{\max }^{*}-\theta^{*}}{\theta_{\max }^{*}}\right)^{C}
$$

$C$ is a parameter representing the roughness, reflecting the evolution of the contact area with the apparent dip angle, and is obtained by the optimal regression method. According to Eq. 4, this paper fits the evolution of $C$ in different range: assuming $A_{0}=0.5, \theta_{\max }{ }^{*}=60^{\circ}, C$ is equal to $4,2,1$, 0.5, 0.3 and 0 respectively, as shown in Fig. 2. For natural rock surfaces, the value of $C$ is usually greater than 1 (Tatone 2009). The contact area is concave with the evolution of the apparent dip angle. In the theoretical state, the value of $C$ also exists from 0 to 1 . 


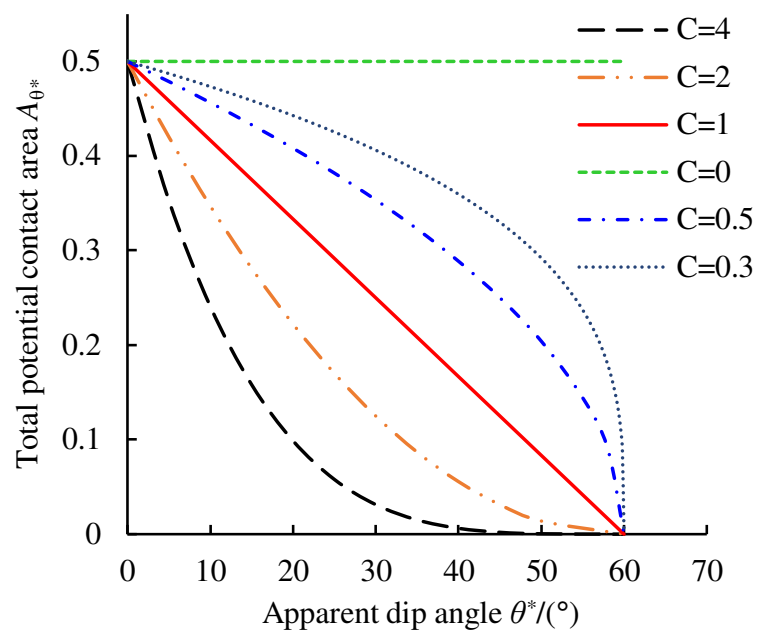

Fig. 2 Evolution of contact area with apparent dip angle and roughness parameter $C$

In order to further understand the effect of $C$ on the morphology of joint surface, this paper studies the two-dimensional average morphology under different $C$ (along the shear direction, use the same continuous two-dimensional graphic representation), as shown in Fig. 3. $C=1$ characterized that apparent dip angle $\left(\theta^{*}\right)$ is linearly related to the potential contact area $\left(A_{\theta^{*}}\right)$, and its two-dimensional average morphology is a circular arc with a constant curvature. $C>1$ characterized that apparent dip angle $\left(\theta^{*}\right)$ is concentrated on the gentle angle, and the curvature of its two-dimensional average morphology is negatively correlated with inclined angle. $C$ approaches infinity characterized a perfectly smooth surface without asperities. $0<C<1$ characterized that apparent dip angle $\left(\theta^{*}\right)$ is concentrated on the steep angle, and the curvature of its two-dimensional average morphology is positively correlated with inclined angle. $C=0$ characterized a saw-tooth profile in which all of the asperities have the same dip angle.
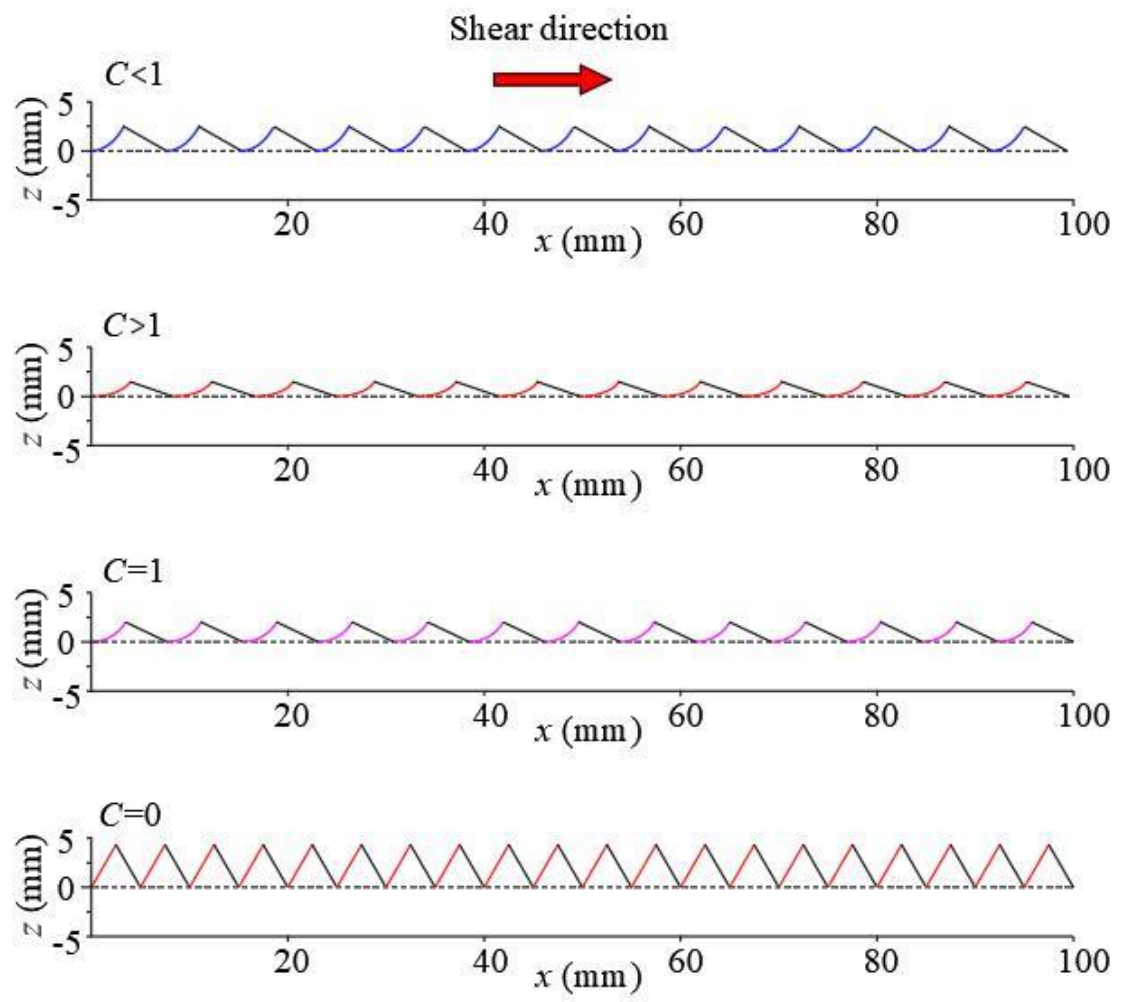
Fig. 3 Two-dimensional average morphology of joints under different $C$

Tatone (2010) discussed the Grasselli's parameters in the two-dimensional situation, using normalized length $\left(L_{\theta^{*}}\right)$ to express the contact area of profile, as shown in Eq. 5.

$$
L_{\theta^{*}}=L_{0}\left(\frac{\theta_{\max }^{*}-\theta^{*}}{\theta_{\max }^{*}}\right)^{C}
$$

Where $L_{0}$ is the normalized length of the profile corresponding to an angular threshold of $0^{\circ}$ in the chosen direction.

The same profile has different inclination angle in the forward and reverse shear directions. In this paper, the $9^{\text {th }}$ standard profile of JRC is called out and reconstructed by GetData Graph Digitizer software, as shown in Fig. 4. In the forward shear direction, when the threshold apparent dip angle takes $0^{\circ}, 10^{\circ}, 20^{\circ}, 30^{\circ}$ and $40^{\circ}$, the corresponding normalized length are $0.673,0.461$, $0.304,0.225$ and 0.119 respectively, as shown in Fig. 5. It can be easily found that threshold apparent dip angle directly affects the contact area, thereby affecting the peak shear strength.

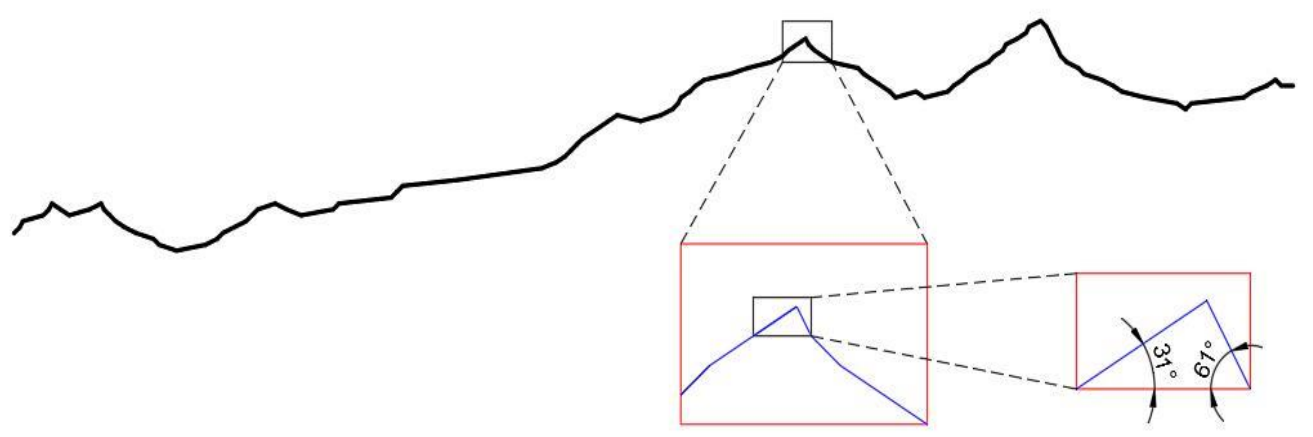

Fig. 4 Geometrical properties of two-dimensional morphology in the forward and reverse of shear direction
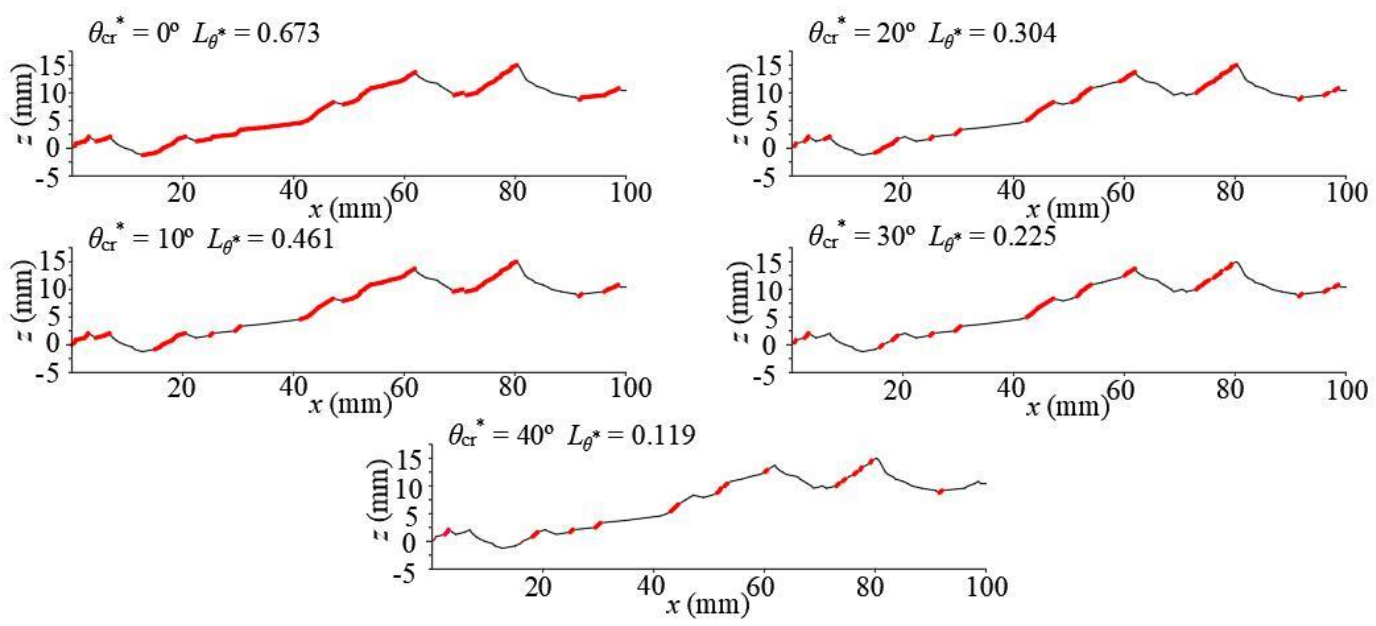

Fig. 5 Evolution of normalized length with threshold apparent dip angle $\theta_{\mathrm{cr}}{ }^{*}$

\subsection{Analysis of Direct Shear Tests by Xia}

In order to study the general mechanism of roughness and normal stress to peak shear strength, Xia's direct shear data is used here (Xia 2014). When studying the influence of normal stress on peak shear strength, it is necessary to make the samples with the same joint surfaces. However, it 
is difficult to find the natural rock surfaces with the same geometrical features. Therefore, Xia (2014) chose three groups of natural rock surfaces as the parent joint samples, and use silicon rubber casts to make a series of model joints at the same scale as the prototype. Then mix plaster, sand, and water at a ratio of 3:2:1 by weight, and pour into the prototype. According to different joint morphologies, the samples were divided into three groups, named I, II and III. The normal stress was divided into 5 groups, which are $0.5,1.0,1.5,2.0$, and 3.0MPa respectively. The shear velocity was controlled at $0.5 \mathrm{~mm} / \mathrm{min}$. The shear tests were conducted until the shear strength reaches the residual strength or the sample was damaged. The test results are shown in Table 1.

Table 1 Experimental results of all direct shear tests (Xia 2014)

\begin{tabular}{|c|c|c|c|c|c|c|c|}
\hline Group & $\begin{array}{c}\sigma_{\mathrm{n}} \\
(\mathrm{MPa})\end{array}$ & $\begin{array}{c}\tau_{\text {peak }} \\
(\mathrm{MPa})\end{array}$ & $\begin{array}{l}\tau_{\text {residual }} \\
(\mathrm{MPa})\end{array}$ & $\tau_{\text {peak }} / \sigma_{\mathrm{n}}$ & $A_{0}$ & $\mathrm{C}$ & $\begin{array}{c}\theta_{\max }{ }^{*} \\
\left(^{\circ}\right)\end{array}$ \\
\hline \multirow[t]{5}{*}{ I } & 0.5 & 0.85 & & 1.70 & 0.499 & 10.5 & 59 \\
\hline & 1.0 & 1.19 & & 1.19 & 0.499 & 10.5 & 59 \\
\hline & 1.5 & 1.77 & & 1.18 & 0.499 & 10.5 & 59 \\
\hline & 2.0 & 2.24 & 1.70 & 1.12 & 0.499 & 10.5 & 59 \\
\hline & 3.0 & 2.84 & 2.20 & 0.95 & 0.499 & 10.5 & 59 \\
\hline \multirow[t]{5}{*}{ II } & 0.5 & 1.13 & 0.89 & 2.26 & 0.504 & 8.01 & 69.3 \\
\hline & 1.0 & 1.75 & 1.56 & 1.75 & 0.504 & 8.01 & 69.3 \\
\hline & 1.5 & 2.20 & 2.00 & 1.47 & 0.504 & 8.01 & 69.3 \\
\hline & 2.0 & 2.78 & 2.44 & 1.39 & 0.504 & 8.01 & 69.3 \\
\hline & 3.0 & 3.34 & & 1.11 & 0.504 & 8.01 & 69.3 \\
\hline \multirow[t]{5}{*}{ III } & 0.5 & 1.78 & 1.55 & 3.56 & 0.688 & 7.48 & 68.7 \\
\hline & 1.0 & 2.42 & 2.03 & 2.42 & 0.688 & 7.48 & 68.7 \\
\hline & 1.5 & 2.89 & 2.54 & 1.93 & 0.688 & 7.48 & 68.7 \\
\hline & 2.0 & 3.51 & 2.99 & 1.76 & 0.688 & 7.48 & 68.7 \\
\hline & 3.0 & 4.20 & 3.56 & 1.40 & 0.688 & 7.48 & 68.7 \\
\hline
\end{tabular}

For joint surfaces with the same morphology (Group I, II, III), the peak shear strength increases with increasing normal stress. However, $\tau_{\mathrm{p}} / \sigma_{\mathrm{n}}$ gradually decreases with increasing normal stress, taking the sample I as an example, as shown in Fig. 6a. In all the 15 sets of direct shear tests, there is no residual strength in the 3 sets of sample I and the 1 set of sample II, it is difficult to establish an effective relationship between residual strength and peak shear strength. The phenomenon that joint surfaces without residual strength in shearing was also occurred in the test results by Grasselli (2001) and Fardin (2008).

The roughness parameter $C$ of the three groups of samples are 10.5, 8.01, and 7.48 respectively. According to the discussion in section 2.1, the roughness of the joint surface increases with the decrease of $C(C>0)$. For applied the same normal stress, taking $\sigma_{\mathrm{n}}=3.0 \mathrm{MPa}$ as an example, as shown in Fig. 6b, the peak shear strength increases with rougher surface. The dilation characteristics under different roughness are shown in Fig. 6c. The dilation increases with rougher surface, i.e., the dilation increases with the decrease of $C(C>0)$. 


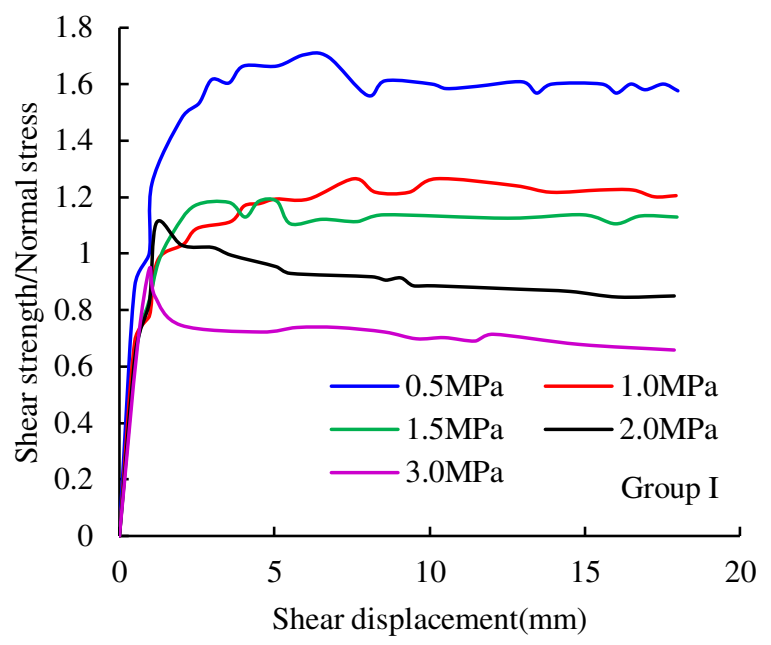

(a) Shear strength/normal stress versus shear displacement for Group I

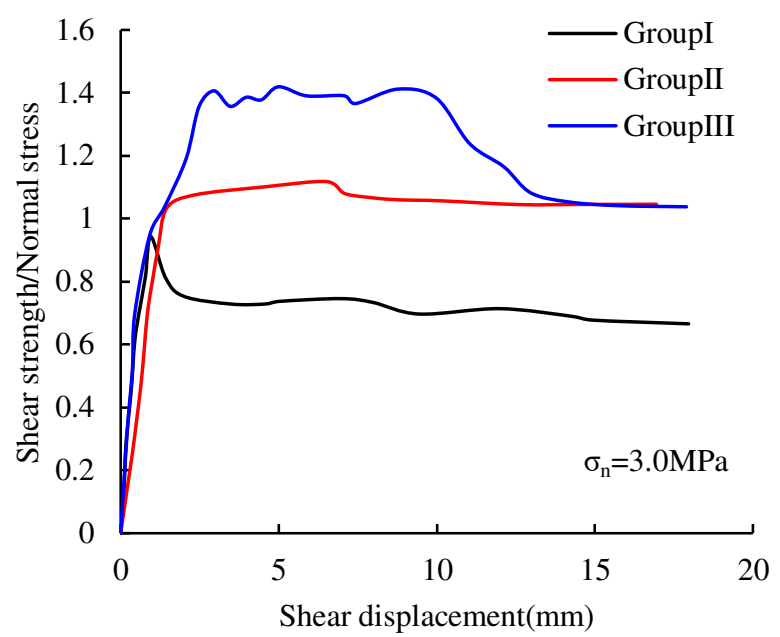

(b) Shear strength/normal stress versus shear displacement with different roughness under $\sigma_{\mathrm{n}}=3.0 \mathrm{MPa}$

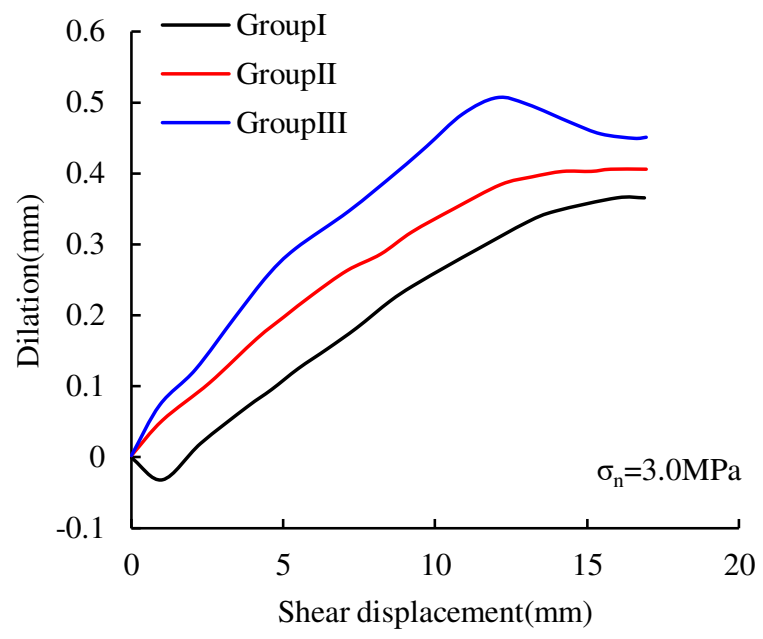

(c) Dilation versus shear displacement with different roughness under $\sigma_{\mathrm{n}}=3.0 \mathrm{MPa}$

Fig. 6 Typical curves of the direct shear tests (Xia 2014)

\subsection{Peak Shear Strength Criterion}

According to Mohr-Coulomb's expression by the ratio of shear-to-normal load, the peak dilation angle can be expressed as: 


$$
\frac{\tau_{\mathrm{p}}}{\sigma_{\mathrm{n}}}=\tan \left(\varphi_{\mathrm{b}}+i_{\mathrm{p}}\right)
$$

Where $\varphi_{\mathrm{b}}$ is the basic friction angle, $i_{\mathrm{p}}$ is the peak dilation angle.

In the JRC-JCS model proposed by Barton and Choubey, the expression of the peak dilation angle is shown in Eq. 7. The main problem with its form is that when the normal stress $\sigma_{\mathrm{n}}$ approaches 0 , the peak dilation angle will tend to infinity, which is inconsistent with reality. In addition, many scholars have found that the predicted results of the JRC-JCS model are generally lower than the actual measured values (Xia 2014, Liu 2017).

$$
i_{\mathrm{p}}=\mathrm{JRC} \cdot \log _{10}\left(\frac{\mathrm{JCS}}{\sigma_{\mathrm{n}}}\right)
$$

Grasselli (2001) hold the opinion that the joint surface has reached residual state, the ratio of shear strength to normal stress is constant. His criterion introduces an amplification factor to the residual friction angle, and uses the amplification factor to express the contribution of roughness and normal stress to the peak shear strength, as shown in Eq. 8.

$$
\left.\begin{array}{l}
\tau_{p}=\sigma_{n}\left[1+\exp \left(-\frac{\theta_{\max }^{*}}{9 A_{0} C} \cdot \frac{\sigma_{n}}{\sigma_{t}}\right)\right] \tan \varphi_{\mathrm{r}}^{*} \\
\varphi_{\mathrm{r}}^{*}=\varphi_{b}+\left(\frac{\theta_{\max }^{*}}{C}\right)^{1.18 \cos \alpha}
\end{array}\right\}
$$

Although the criterion proposed by Grasselli is based on three-dimensional morphology and the predicted peak shear strength with acceptable precision, it has following limitations:

1. Grasselli's criterion dose not satisfies the Mohr-Coulomb law, which cannot reflect the evolution of dilation angle in shearing.

2. The contribution of roughness and normal stress to the peak shear strength is expressed by the amplification factor, and the residual friction angle is constant. However, according to the discussion in section 2.2 , the joint surface does not necessarily produce a residual state.

3. For smooth joint surface, the maximum apparent dip angle $\left(\theta_{\max }{ }^{*}\right)$ is 0 . The Eq. 8 is simplified to $\tau_{\mathrm{p}}=2 \sigma_{\mathrm{n}} \tan \left(\varphi_{\mathrm{b}}\right)$, which is not consistent with the peak shear strength $\tau_{\mathrm{p}}=\sigma_{\mathrm{n}} \tan \left(\varphi_{\mathrm{b}}\right)$ for smooth joint surface.

4. The roughness in criterion is expressed as $\theta_{\max }{ }^{*} / C$, where the denominator is composed of $C$. Therefore, the criterion cannot reflect the saw-tooth joints with $C=0$.

Tatone (2009) integrated the potential contact area $\left(A_{\theta^{*}}\right)$ between $\left[0, \theta_{\max }{ }^{*}\right]$, and defined the average apparent dip angle $\left(\theta_{\text {avg }}\right)$.

$$
\theta_{\text {avg }}=\frac{\int_{0}^{\theta_{\max }^{*}} A_{0}\left(\frac{\theta_{\max }^{*}-\theta^{*}}{\theta_{\max }^{*}}\right)^{C} \mathrm{~d} \theta^{*}}{A_{0}}=\frac{\theta_{\max }^{*}}{C+1}
$$

Xia (2015) introduced the average apparent dip angle into his criterion, which satisfies the Mohr-Coulomb law (Eq. 10). In the expression of peak dilation angle, $i_{\mathrm{p}}=8 A_{0} \theta_{\max }{ }^{*} /(C+1)$ when $\sigma_{\mathrm{n}}$ approaches $0, i_{\mathrm{p}}=4 A_{0} \theta_{\max }{ }^{*} /(C+1)$ when $\sigma_{\mathrm{n}}$ approaches infinity. The peak dilation angle is always greater than half of the initial dilation angle, which deviates from the actual evolution relationship. 


$$
\tau_{\mathrm{p}}=\sigma_{\mathrm{n}} \tan \left\{\varphi_{\mathrm{b}}+\frac{4 A_{0} \theta_{\max }^{*}}{C+1}\left[1+\exp \left(-\frac{1}{9 A_{0}} \frac{\theta_{\max }^{*}}{C+1} \frac{\sigma_{\mathrm{n}}}{\sigma_{\mathrm{t}}}\right)\right]\right\}
$$

Regarding the evolution of the peak dilation angle with normal stress, the generally accepted boundary conditions are as follow (Yang 2016):

$$
i_{p}= \begin{cases}i_{0} & \sigma_{n} \rightarrow 0 \\ 0 & \sigma_{n} \rightarrow \infty\end{cases}
$$

Where $i_{0}$ is the initial dilation angle.

The functional relationship between the peak dilation angle and normal stress mainly has three forms: exponential function, logarithmic function and power function (Barton 1977, Schneider 1976, Zhang 2016, Yang 2016), as shown in Eq. 12.

$$
\begin{aligned}
& i_{p}=i_{0}\left[1-\exp \left(-K \frac{\sigma_{i}}{\sigma_{n}}\right)\right] \\
& i_{p}=i_{0} \exp \left(-K \frac{\sigma_{n}}{\sigma_{i}}\right) \\
& i_{p}=i_{0} \log _{10}\left(-\frac{\sigma_{i}}{\sigma_{n}}\right) \\
& i_{p}=i_{0}\left(1-\frac{\sigma_{n}}{\sigma_{i}}\right)^{K}
\end{aligned}
$$

Where $K$ is the attenuation correction coefficient, which is related to roughness and material. $\sigma_{\mathrm{i}}$ is the tensile strength $\left(\sigma_{t}\right)$ or the compressive strength $\left(\sigma_{c}\right)$ of the material.

In the test results of Grasselli (2003) and Xia (2014), there is a common feature, the peak dilation angle has a negative exponential relationship with the evolution of the normal stress. Based on this, a new criterion in this paper chooses $i_{\mathrm{p}}=i_{0} \exp \left(-K \sigma_{\mathrm{n}} / \sigma_{\mathrm{i}}\right)$ to express the peak dilation angle.

Although tensile strength $\left(\sigma_{\mathrm{t}}\right)$ is selected as $\sigma_{\mathrm{i}}$ in Grasselli's criterion, he found that $\tau_{\mathrm{p}} / \sigma_{\mathrm{n}}$ tends to stabilize when $\sigma_{\mathrm{n}} / \sigma_{\mathrm{c}}$ approaches 0.2 (Grasselli 2003). The same situation does not appear in $\sigma_{\mathrm{n}} / \sigma_{\mathrm{t}}$, indicating that the effect of normal stress on peak shear strength is related to compressive strength in different rock joints. Therefore, the new criterion in this paper selects compressive strength $\left(\sigma_{c}\right)$ as $\sigma_{\mathrm{i}}$.

In the expression of the initial dilation angle ( $\left.i_{0}\right)$, the criteria of Grasselli (2003) and Xia (2014) both use the combination of roughness parameter $(C)$ and maximum apparent dip angle $\left(\theta_{\max }{ }^{*}\right)$. Using Grasselli's roughness parameter data before and after shearing, the changes of different combined parameters are studied, as shown in Table. 2.

Table 2 Variation of the combined parameters characterizing joint roughness before and after shearing (Grasselli 2002)

\begin{tabular}{cccccc}
\hline $\begin{array}{c}\text { sample } \\
\text { number }\end{array}$ & $\theta_{\text {max }}{ }^{*}$ & $C$ & $\theta_{\max }{ }^{*} / C$ & $\begin{array}{c}\theta_{\max }{ }^{*} / \\
(C+1)\end{array}$ & $\begin{array}{c}\theta_{\max }{ }^{*} / \\
(C+1)^{0.45}\end{array}$ \\
\hline C2(fresh) & 80 & 5.64 & 14.19 & 12.05 & 34.13 \\
C2(after one sheared) & 65 & 4.19 & 15.51 & 12.52 & 30.98 \\
G9(fresh) & 75 & 5.85 & 12.81 & 10.95 & 31.55 \\
\hline
\end{tabular}




\begin{tabular}{cccccc}
\hline G9(after one sheared) & 65 & 4.85 & 13.4 & 11.11 & 29.36 \\
M12(fresh) & 55 & 7.28 & 7.55 & 6.64 & 21.24 \\
M12(after one sheared) & 55 & 7.14 & 7.71 & 6.76 & 21.41 \\
ML2(fresh) & 55 & 5.66 & 9.73 & 8.26 & 23.43 \\
ML2(after one sheared) & 55 & 5.55 & 9.91 & 8.4 & 23.61 \\
\hline
\end{tabular}

The decrease of $\theta_{\max }{ }^{*}$ indicates that the steeply asperity became smaller after shearing. The decrease of $C$ after shearing indicates that shearing made the asperity distribution more uniform. Grasselli (2003) used $\theta_{\max }{ }^{*} / C$ to represent the amplification factor of residual friction. Xia (2014) used average apparent dip angle $\theta_{\max }{ }^{*} /(C+1)$ to represent the initial dilation angle. However, there is an obvious problem with these two criteria. After the sample is sheared once, both the amplification factor and the initial dilation angle appear to increase. When the normal stress approaches 0 , the peak shear strength calculated by Eq. 8 and 10 after first shear will greater than the peak shear strength at first shear, which is inconsistent with the actual test results.

Yang (2016) obtained the peak dilation angle based on the boundary conditions (Eq. 13). However, $C$ is the denominator in the initial dilation angle, Yang's criterion cannot reflect the saw-tooth joints. Moreover, Yang's criterion does not consider the influence of the maximum contact area $\left(A_{0}\right)$ on the peak shear strength.

$$
\tau_{\mathrm{p}}=\sigma_{\mathrm{n}} \tan \left[\varphi_{\mathrm{b}}+\frac{\theta_{\max }^{*}}{C^{0.45}} \exp \left(-\frac{\sigma_{\mathrm{n}}}{\sigma_{\mathrm{c}}} C^{0.75}\right)\right]
$$

In the expression of the initial dilation angle of the new criterion, a correction coefficient $(m)$ is attached to the average apparent dip angle $\theta_{\max }{ }^{*} /(C+1)$. The maximum apparent dip angle $\left(\theta_{\max }{ }^{*}\right)$ only determines the evolution of the dilatancy angle at the initial stage of shearing. Therefore, the attenuation correction coefficient $(K)$ is represented by $C+1$ and a correction coefficient $(n)$.

$$
i_{\mathrm{p}}=\left[\frac{\theta_{\max }^{*}}{(C+1)^{m}}\right] \exp \left[-\frac{\sigma_{\mathrm{n}}}{\sigma_{\mathrm{c}}}(C+1)^{n}\right]
$$

According to 37 sets of direct shear test data of Grasselli and 20 sets of direct shear test data of Yang, as shown in Table 3, $m=0.45$ and $n=0.75$ are obtained by optimal regression analysis.

\begin{tabular}{|c|c|c|c|c|c|c|c|c|c|c|c|c|c|}
\hline \multirow{2}{*}{$\begin{array}{l}\text { Sample } \\
\text { number }\end{array}$} & \multirow{2}{*}{$\begin{array}{c}\text { Rock } \\
\text { species }\end{array}$} & \multirow{2}{*}{$\begin{array}{c}\sigma_{n} \\
(\mathrm{MPa})\end{array}$} & \multirow{2}{*}{$A_{0}$} & \multirow{2}{*}{$C$} & \multirow{2}{*}{$\begin{array}{c}\theta_{\max }{ }^{*} \\
\left(^{\circ}\right)\end{array}$} & \multirow{2}{*}{$\begin{array}{c}\beta \varphi b \\
\left(^{\circ}\right)\left(^{\circ}\right)\end{array}$} & \multirow{2}{*}{$\begin{array}{c}\sigma_{t} \\
(\mathrm{MPa})\end{array}$} & \multirow{2}{*}{$\begin{array}{c}\sigma_{c} \\
(\mathrm{MPa})\end{array}$} & \multicolumn{5}{|c|}{ Peak shear strenghth $\tau_{\mathrm{p}}(\mathrm{MPa})$} \\
\hline & & & & & & & & & Measured & Grasselli & Tang & Yang & New \\
\hline $\mathrm{C} 1$ & limestone & 1.07 & 0.491 & 7.03 & 80 & 36 & 2.4 & 25 & 2.2 & 1.91 & 2.08 & 2.16 & 1.97 \\
\hline $\mathrm{C} 2$ & limestone & 1.07 & 0.462 & 5.64 & 80 & 36 & 2.4 & 25 & 2.1 & 2.16 & 2.23 & 2.57 & 2.21 \\
\hline $\mathrm{C} 3$ & limestone & 3.72 & 0.46 & 4.6 & 57 & 36 & 2.4 & 25 & 5.5 & 5.46 & 5.34 & 5.12 & 4.52 \\
\hline $\mathrm{C} 4$ & limestone & 2.45 & 0.508 & 4.74 & 65 & 36 & 2.4 & 25 & 4.6 & 4.1 & 4.39 & 4.17 & 3.73 \\
\hline $\mathrm{C} 5$ & limestone & 3.11 & 0.495 & 5.26 & 74 & 36 & 2.4 & 25 & 5 & 5.19 & 5.42 & 5.13 & 4.56 \\
\hline C6 & limestone & 1.02 & 0.546 & 5.19 & 68 & 36 & 2.4 & 25 & 2.1 & 2.06 & 2.7 & 2.11 & 1.91 \\
\hline $\mathrm{C} 8$ & limestone & 3.11 & 0.555 & 5.71 & 74 & 36 & 2.4 & 25 & 4.9 & 4.87 & 5.82 & 4.85 & 4.56 \\
\hline G1 & granite & 2.3 & 0.493 & 7.17 & 90 & 34 & 8.8 & 173 & 5.7 & 4.64 & 5.44 & 5.99 & 5.36 \\
\hline G2 & granite & 2.3 & 0.498 & 5.6 & 80 & 34 & 8.8 & 173 & 5.6 & 5.09 & 6.34 & 6.03 & 5.26 \\
\hline G4 & granite & 2.19 & 0.498 & 5.48 & 65 & 34 & 8.8 & 173 & 4.8 & 4.33 & 4.79 & 4.28 & 3.89 \\
\hline G5 & granite & 1.12 & 0.46 & 5.33 & 57 & 34 & 8.8 & 173 & 2.4 & 2.33 & 2.21 & 1.96 & 1.8 \\
\hline
\end{tabular}

Table 3 Data of direct shear tests (Grasselli 2003, Yang 2015) 


\begin{tabular}{|c|c|c|c|c|c|c|c|c|c|c|c|c|c|}
\hline G6 & granite & 1.12 & 0.477 & 7.39 & 84 & 34 & 8.8 & 173 & 2.9 & 2.42 & 2.68 & 2.66 & 2.42 \\
\hline G7 & granite & 1.12 & 0.47 & 7.15 & 81 & 34 & 8.8 & 173 & 2.8 & 2.41 & 2.58 & 2.57 & 2.35 \\
\hline G9 & granite & 1.12 & 0.508 & 5.85 & 75 & 34 & 8.8 & 173 & 3 & 2.65 & 3.59 & 2.65 & 2.37 \\
\hline Gn3 & gneiss & 2.65 & 0.492 & 8.11 & 65 & 9036 & 9.5 & 184 & 2.4 & 3.2 & 4.41 & 4.53 & 2.63 \\
\hline Gn6 & gneiss & 1.9 & 0.522 & 4.91 & 63 & 036 & 3.5 & 160 & 3.4 & 3.5 & 4.03 & 4.19 & 3.75 \\
\hline Gn9 & gneiss & 3.52 & 0.488 & 8.12 & 63 & 9036 & 9.5 & 184 & 4 & 4.03 & 5.42 & 5.72 & 3.44 \\
\hline Gn10 & gneiss & 3.57 & 0.5 & 8.18 & 70 & 9036 & 9.5 & 184 & 3.9 & 4.01 & 6.02 & 6.38 & 3.57 \\
\hline Gn11 & gneiss & 3.52 & 0.432 & 10.28 & 74 & 9036 & 9.5 & 184 & 4.3 & 3.99 & 4.74 & 5.91 & 3.46 \\
\hline Gn12 & gneiss & 4.08 & 0.506 & 11.12 & 85 & 9036 & 9.5 & 184 & 3.3 & 4.57 & 6.41 & 7.40 & 4.09 \\
\hline Gn13 & gneiss & 2.6 & 0.503 & 9.17 & 74 & 9036 & 9.5 & 184 & 3.5 & 3.16 & 4.52 & 4.76 & 2.62 \\
\hline M1 & marble & 0.87 & 0.513 & 9.64 & 76 & 37 & 9.2 & 87 & 1.7 & 1.82 & 1.81 & 1.70 & 1.62 \\
\hline M2 & marble & 1.73 & 0.492 & 5.6 & 39 & 37 & 9.2 & 87 & 2.3 & 3.22 & 2.73 & 2.36 & 2.24 \\
\hline M3 & marble & 0.87 & 0.471 & 10.5 & 65 & 37 & 9.2 & 87 & 1.2 & 1.66 & 1.34 & 1.41 & 1.35 \\
\hline M4 & marble & 3.78 & 0.513 & 8.12 & 61 & 37 & 9.2 & 87 & 5.8 & 6.3 & 6.12 & 5.67 & 5.41 \\
\hline M5 & marble & 2.6 & 0.533 & 8.92 & 59 & 37 & 9.2 & 87 & 4.4 & 4.56 & 4.26 & 3.84 & 3.71 \\
\hline M6 & marble & 2.6 & 0.45 & 10.18 & 68 & 37 & 9.2 & 87 & 4.3 & 4.44 & 3.73 & 4.03 & 3.82 \\
\hline M7 & marble & 3.78 & 0.502 & 13.33 & 86 & 37 & 9.2 & 87 & 5.6 & 6.1 & 5.61 & 5.78 & 5.58 \\
\hline M8 & marble & 3.83 & 0.459 & 10.52 & 72 & 37 & 9.2 & 87 & 6.4 & 6.1 & 5.39 & 5.74 & 5.42 \\
\hline M9 & marble & 2.6 & 0.494 & 10.36 & 59 & 37 & 9.2 & 87 & 4.5 & 4.38 & 3.66 & 3.62 & 3.5 \\
\hline M10 & marble & 0.87 & 0.515 & 10.79 & 67 & 37 & 9.2 & 87 & 1.5 & 1.67 & 1.46 & 1.43 & 1.38 \\
\hline M12 & marble & 1.79 & 0.429 & 7.28 & 55 & 37 & 9.2 & 87 & 3 & 3.33 & 2.71 & 2.82 & 2.64 \\
\hline ML1 & sandstone & 1.02 & 0.573 & 7.25 & 66 & 37 & 0.7 & 10 & 1.4 & 1.33 & 1.59 & 1.42 & 1.38 \\
\hline ML2 & sandstone & 4.13 & 0.505 & 5.44 & 45 & 37 & 0.7 & 10 & 4.5 & 4.77 & 5.12 & 3.7 & 3.56 \\
\hline ML3 & sandstone & 2.09 & 0.523 & 7.81 & 66 & 37 & 0.7 & 10 & 2.3 & 2.45 & 2.75 & 2.23 & 2.16 \\
\hline S1 & serpentinite & 1.94 & 0.504 & 4.8 & 79 & $\begin{array}{ll}0 & 39\end{array}$ & 6 & 166 & 4.3 & 5.77 & 8.31 & 8.11 & 6.47 \\
\hline S2 & serpentinite & 0.97 & 0.466 & 4.44 & 75 & $\begin{array}{ll}0 & 39\end{array}$ & 6 & 166 & 3.4 & 3.49 & 5.39 & 4.09 & 3.22 \\
\hline GR1 & granite & 0.8 & 0.61 & 10.26 & 79.67 & 34 & 8.8 & 161 & 1.5 & 1.52 & 1.85 & 1.45 & 1.39 \\
\hline GR2 & granite & 1.6 & 0.53 & 9.85 & 81.76 & 34 & 8.8 & 161 & 3.1 & 2.88 & 3 & 2.96 & 2.82 \\
\hline GR3 & granite & 2.4 & 0.48 & 10.08 & 83.67 & 34 & 8.8 & 161 & 4.8 & 3.98 & 3.77 & 4.36 & 4.12 \\
\hline GR4 & granite & 3.2 & 0.51 & 9.28 & 82.06 & 34 & 8.8 & 161 & 5.8 & 5.15 & 5.31 & 5.79 & 5.48 \\
\hline GR5 & granite & 4 & 0.47 & 10.41 & 79.32 & 34 & 8.8 & 161 & 6.4 & 5.76 & 5.36 & 6.38 & 6.05 \\
\hline GR6 & granite & 4.8 & 0.49 & 10.82 & 81.58 & 34 & 8.8 & 161 & 7.3 & 6.65 & 6.44 & 7.5 & 7.15 \\
\hline GR7 & granite & 5.6 & 0.53 & 11.17 & 81.06 & 34 & 8.8 & 161 & 8.5 & 7.56 & 7.69 & 8.34 & 8.08 \\
\hline GR8 & granite & 6.4 & 0.56 & 9.56 & 84.05 & 34 & 8.8 & 161 & 11 & 8.79 & 10.04 & 10.45 & 10.1 \\
\hline GR9 & granite & 7.2 & 0.51 & 9.61 & 82.59 & 34 & 8.8 & 161 & 11.2 & 9.28 & 9.85 & 11.25 & 10.69 \\
\hline GR10 & granite & 8 & 0.53 & 8.3 & 82.23 & 34 & 8.8 & 161 & 12.7 & 10.58 & 11.96 & 13.25 & 12.55 \\
\hline S1 & sandstone & 0.325 & 0.51 & 8.85 & 83.32 & 28 & 2.6 & 65 & 0.7 & 0.52 & 0.54 & 0.53 & 0.5 \\
\hline S2 & sandstone & 0.65 & 0.61 & 7.61 & 82.27 & 28 & 2.6 & 65 & 0.9 & 1.03 & 1.49 & 1.1 & 1.04 \\
\hline S3 & sandstone & 0.975 & 0.54 & 8.39 & 82.6 & 28 & 2.6 & 65 & 1.5 & 1.33 & 1.48 & 1.53 & 1.44 \\
\hline S4 & sandstone & 1.3 & 0.49 & 8.92 & 83.85 & 28 & 2.6 & 65 & 2 & 1.58 & 1.6 & 1.95 & 1.83 \\
\hline S5 & sandstone & 1.625 & 0.55 & 9.52 & 82.72 & 28 & 2.6 & 65 & 2.1 & 1.87 & 2.06 & 2.25 & 2.17 \\
\hline S6 & sandstone & 1.95 & 0.58 & 7.92 & 81.62 & 28 & 2.6 & 65 & 3 & 2.29 & 2.78 & 2.88 & 2.75 \\
\hline
\end{tabular}




\begin{tabular}{cccccccccccccc}
\hline S7 & sandstone & 2.275 & 0.5 & 8.93 & 82.86 & 28 & 2.6 & 65 & 3.3 & 2.37 & 2.53 & 3.11 & 2.94 \\
S8 & sandstone & 2.6 & 0.47 & 8.84 & 83.53 & 28 & 2.6 & 65 & 3.6 & 2.61 & 2.7 & 3.52 & 3.28 \\
S9 & sandstone & 2.925 & 0.44 & 9.27 & 83.35 & 28 & 2.6 & 65 & 3.8 & 2.77 & 2.8 & 3.76 & 3.46 \\
S10 & sandstone & 3.25 & 0.51 & 8.34 & 84.21 & 28 & 2.6 & 65 & 4.7 & 3.26 & 3.61 & 4.37 & 4.12 \\
\hline
\end{tabular}

$A_{0}$ reflects the maximum contact area of the joint surface, which is positively correlated with peak shear strength. However, it is uncertain whether to attach the influence of $A_{0}$ to the initial dilation angle $\left(i_{0}\right)$ or the attenuation correction coefficient $(K)$. Therefore, the three cases where $A_{0}$ is attached to the initial dilation angle, $A_{0}$ is attached to the attenuation correction coefficient, and $A_{0}$ is not included in criterion are compared.

$$
\begin{aligned}
& \tau_{\mathrm{p}}=\sigma_{\mathrm{n}} \tan \left\{\varphi_{\mathrm{b}}+\left[\frac{\theta_{\max }^{*}}{(C+1)^{0.45}}\right] \exp \left[-\frac{\sigma_{\mathrm{n}}}{\sigma_{\mathrm{c}}} \frac{(C+1)^{0.75}}{2 A_{0}}\right]\right\} \\
& \tau_{\mathrm{p}}=\sigma_{\mathrm{n}} \tan \left\{\varphi_{\mathrm{b}}+\left[\frac{2 A_{0} \cdot \theta_{\max }^{*}}{(C+1)^{0.45}}\right] \exp \left[-\frac{\sigma_{\mathrm{n}}}{\sigma_{\mathrm{c}}}(C+1)^{0.75}\right]\right\} \\
& \tau_{\mathrm{p}}=\sigma_{\mathrm{n}} \tan \left\{\varphi_{\mathrm{b}}+\left[\frac{\theta_{\max }^{*}}{(C+1)^{0.45}}\right] \exp \left[-\frac{\sigma_{\mathrm{n}}}{\sigma_{\mathrm{c}}}(C+1)^{0.75}\right]\right\}
\end{aligned}
$$

The 37 sets of data of Grasselli were analyzed, and the results are shown in Fig. 7. The average relative errors $\left(\delta_{\text {avg }}\right)$ of Eq. 15, 16 and 17 are 13.3\%, 24.2\% and 23.5\% respectively. In contrast, it is more reasonable to add $A_{0}$ to the attenuation correction coefficient.

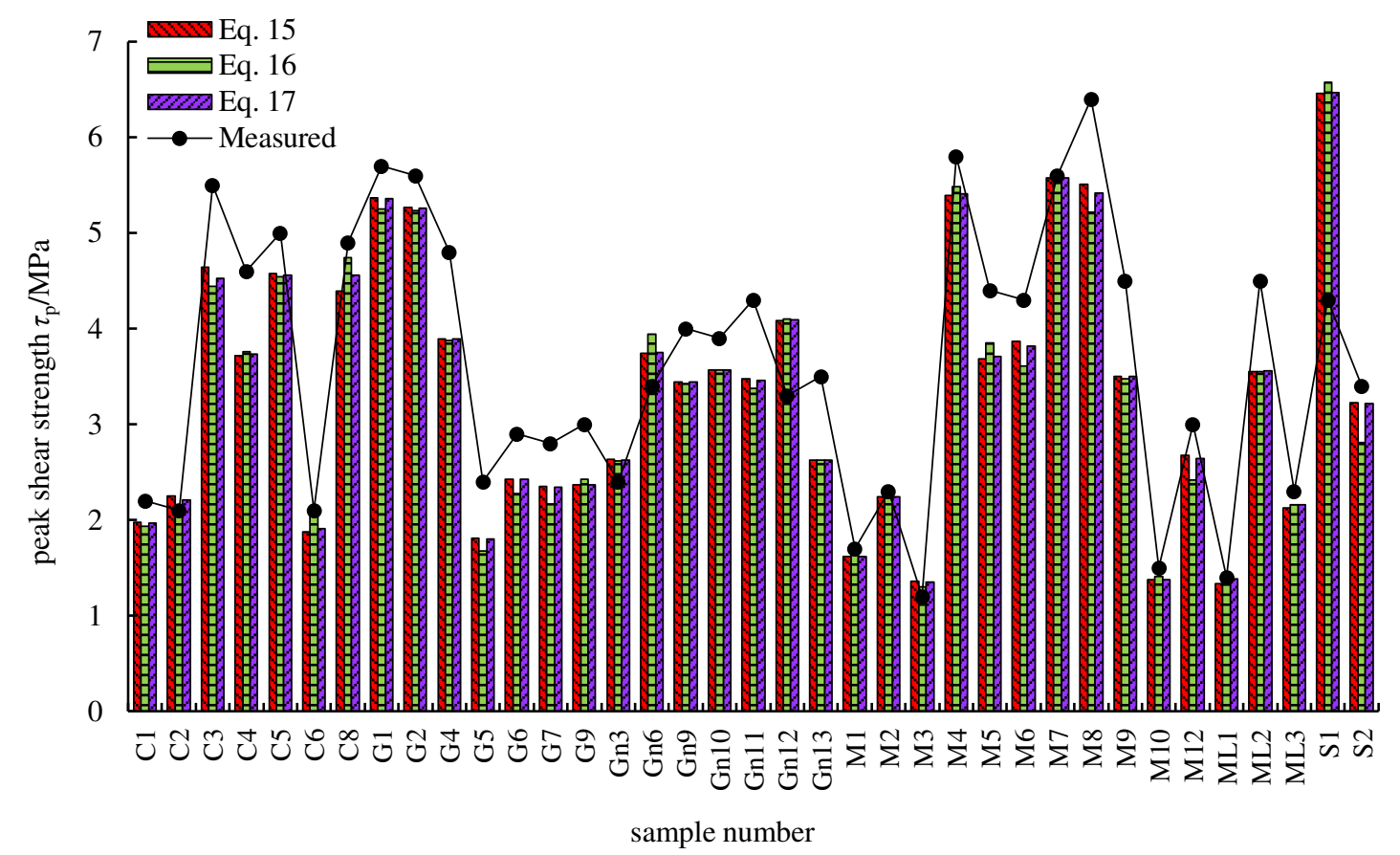

Fig.7 Comparison of measured values and calculated values based on Grasselli's test data

In natural rock joints, metamorphic rock often have structure in which minerals are arranged oriented, namely, schistosity structure. The original fixed roughness along the shear direction, due to the appearance of the schistosity structure, causing the peak shear strength to decrease. The failure process of the original joint surface is not affected (controlled by the effective shear inclination and contact area). Therefore, the influence of schistosity structure is attached to the 
initial dilation angle. The initial dilation angle is empirically corrected based on the test data of Grasselli. The initial dilation angle before and after correction is shown in Eq. 18 and 19.

$$
\begin{gathered}
i_{01}=\frac{\theta_{\max }^{*}}{(C+1)^{0.45}} \\
i_{02}=\left[\frac{\theta_{\max }^{*}}{(C+1)^{0.45}}\right]^{\cos \left(\frac{\beta}{2}\right)}
\end{gathered}
$$

Where $\beta$ is the angle between the normal plane of the joint and the schistosity plane.

The predicted values before and after the correction are compared with the measured values, as shown in Fig. 8. The peak shear strength of the schistosity rock with $\beta=90^{\circ}$ is reduced by 22.4 53.2\%. Corrected by introducing $\beta$ into the initial dilation angle, the relative error after correction is $8.5 \sim 25 \%$. After the correction, the agreement between the predicted value and the measured value is significantly improved.

Combining all the discussions above, the final form of the new criterion is:

$$
\tau_{p}=\sigma_{n} \tan \left\{\varphi_{b}+\left[\frac{\theta_{\max }^{*}}{(C+1)^{0.45}}\right]^{\cos \left(\frac{\beta}{2}\right)} \exp \left[-\frac{\sigma_{n}}{\sigma_{c}} \frac{(C+1)^{0.75}}{2 A_{0}}\right]\right\}
$$

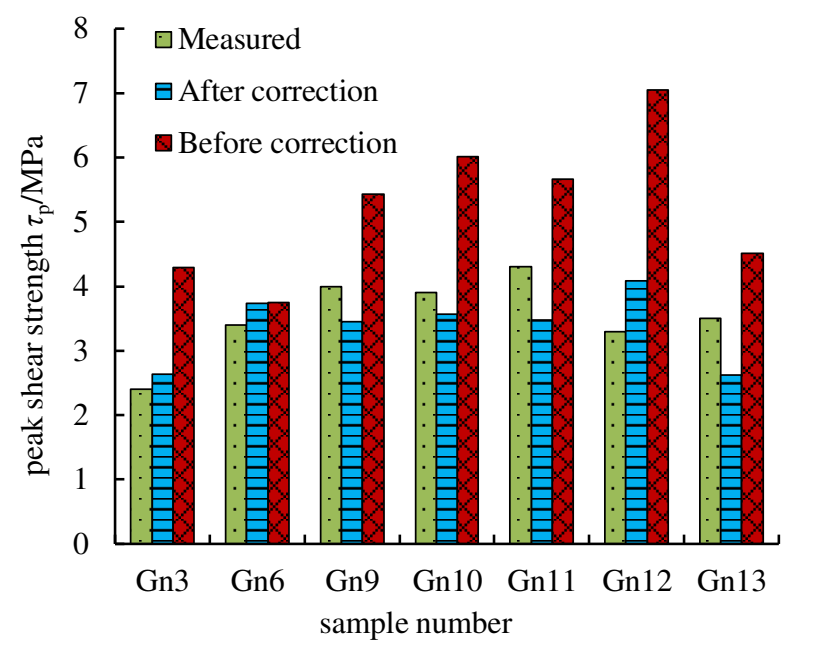

Fig. 8 Comparison of measured values and calculations before and after initial dilation correction

\subsection{Accuracy of Predicted Value of New Criterion}

The accuracy of the new criterion is verified through 57 sets of test data of Grasselli (2003) and Yang (2015). The measured values and prediction results of different criteria are shown in Table 3. The fitting quality of the predicted value and the measured value is determined by the average value of the error and the degree of deviation of the error. In this paper, the average relative error ( $\left.\delta_{\text {avg }}\right)$ is used to represent the average value of the error, the standard deviation $(\mu)$ of the relative error is used to represent the degree of error deviation.

$$
\begin{gathered}
\delta_{\text {avg }}=\frac{1}{n} \sum_{\mathrm{i}=1}^{n} \frac{\left|\tau_{\mathrm{mi}}-\tau_{\mathrm{ci}}\right|}{\tau_{\mathrm{mi}}} \times 100 \% \\
\mu=\sqrt{\frac{1}{n} \sum_{\mathrm{i}=1}^{\mathrm{n}}\left(\delta_{\mathrm{i}}-\delta_{\text {avg }}\right)^{2}}
\end{gathered}
$$


Where $\tau_{\mathrm{mi}}$ is the measured value of the $\mathrm{i}^{\text {th }}$ group, $\tau_{\mathrm{ci}}$ is the predicted value of the $\mathrm{i}^{\text {th }}$ group, $n$ is the total number of tests, $\delta_{\mathrm{i}}$ is the relative error of the $\mathrm{i}^{\text {th }}$ group.

The average relative error $\left(\delta_{\text {avg }}\right)$ and the standard deviation $(\mu)$ of the relative error of three criteria are shown in Table. 4.

Table 4 Comparative analysis of the predicted value of peak shear strength

\begin{tabular}{ccccccc}
\hline \multirow{2}{*}{ Criterion } & \multicolumn{2}{c}{ data of Grasselli } & \multicolumn{2}{c}{ data of Yang } & \multicolumn{2}{c}{ all 57 sets of data } \\
\cline { 2 - 7 } & $\delta_{\text {avg }}(\%)$ & $\mu(\%)$ & $\delta_{\text {avg }}(\%)$ & $\mu(\%)$ & $\delta_{\text {avg }}(\%)$ & $\mu(\%)$ \\
\hline \multirow{2}{*}{ Grasselli } & 11 & 11.4 & 17.1 & 8.9 & 13.1 & 10.6 \\
Tang & 20.7 & 24.4 & 16.9 & 14 & 19.4 & 21.3 \\
Yang & 20.2 & 28.2 & 5.5 & 11.5 & 15.0 & 23.7 \\
New & 13.3 & 9.3 & 8.6 & 6.7 & 11.7 & 8.5 \\
\hline
\end{tabular}

For Grasselli's data, the $\delta_{\text {avg }}$ of the new criterion is $13.3 \%$, which is slightly higher than the $\delta_{\text {avg }}$ of the Grasselli's criterion (11\%). For Ynag's data, the $\delta_{\text {avg }}$ of the new criterion is $8.6 \%$, which is slightly higher than the $\delta_{\text {avg }}$ of the Yang's criterion (5.5\%). For all 57 sets of test data, the $\delta_{\text {avg }}$ of the new criterion is the smallest, which is $11.7 \%$. Regardless of the data from Grasselli and Yang, the new criterion has the smallest $\mu$. In contrast, the predicted value of new criterion is more consistent with the teat data than other criteria.

\section{Conclusion}

This paper gives a detailed explanation of the three-dimensional roughness parameters proposed by Grasselli, and discusses the morphology characteristics of the joint surface when the roughness parameter $C$ in different ranges. Based on theory and test, a new criterion satisfying Mohr-Coulomb law is proposed that the nonlinear characteristic of peak shear strength is included in the peak dilation angle. In the new criterion, the evolution of the peak dilation angle meets the boundary conditions. In order to make the new criterion satisfy that the peak shear strength after first shear is less than the peak shear strength at first shear, the average apparent dip angle $\theta_{\max }{ }^{*} /(C+1)$ is improved, using $\theta_{\max }{ }^{*} /(C+1)^{0.45}$ to represents the initial dilation angle. In addition, the new criterion takes into account the influence of the maximum contact area and schistosity structure on the peak shear strength.

By quoting the test data of Grasselli and Yang, the prediction results of different criteria are compared, and it is found that the new criterion has the highest degree of agreement with the test results.

Although many research has focused on the expression method of rock joint roughness and the criterion of peak shear strength, there are few attempt is made to investigate the relationship between roughness scale effects and shear strength scale effects. Subsequent research will further reveal the shear mechanism of rock joints.

\section{Acknowledgments}

The authors gratefully acknowledge the financial support from National Key R \& D Plan (2017YFC0404904), a research (51509163, U1765203) grant from National Natural Science Foundation of China. And a research grant (201501035) from Special fund project for water conservancy industry.

\section{Reference}

Ban LR, Qi CZ, Chen HX et al (2020) A new criterion for peak shear strength of rock joints with a 3D roughness 
parameter. Rock Mech Rock Eng 53:1755-1775. https://doi.org/10.1007/s00603-019-02007-Z

Ban LR, Zhu C, Qi CZ et al (2018) New roughness parameters for 3D roughness of rock joints. Bull Eng Geol Environ. https://doi.org/10.1007/s10064-018-1394-3

Barton N, Choubey V (1977) The shear strength of rock joints in theory and practice. Rock Mech Rock Eng 10:1-51. https://doi.org/10.1007/BF01261801

Belem T, Homand F, Souley M (2000) Quantitative parameters for rock joint surface roughness. Rock Mech Rock Eng 33:217-242. https://doi.org/10.1007/s006030070001

Fardin N (2008) Influence of structural non-stationarity of surface roughness on morphological characterization and mechanical deformation of rock joints. Rock Mech Rock Eng 41:267-297. https://doi.org/10.1007/s00603-007-0144-9

Grasselli G (2001) Shear strength of rock joints based on quantified surface description. Dissertation, Swiss Federal Institute of Technology.

Grasselli G, Egger P (2003) Constitutive law for the shear strength of rock joints based on three-dimensional surface parameters. Int J Rock Mech Min Sci 40:25-40. https://doi.org/10.1016/S1365-1609(02)00101-6

Grasselli G, Wirth J, Egger P (2002) Quantitative three-dimensional description of a rough surface and parameter evolution with shearing. Int J Rock Mech Min Sci 39:789-800. https://doi.org/ 10.1016/S1365-1609(02)00070-9

International Society for Rock Mechanics (ISRM) (1978) Suggested methods for the quantitative description of discontinuities in rock masses. Int $\mathrm{J}$ Rock Mech Min Sci Geomech Abstr 15:319-368. https://doi.org/10.1016/0148-9062(78)91472-9

Jang HS, Kang SS, Jang BA (2014) Determination of joint roughness coefficients using roughness parameters. Rock Mech Rock Eng 47:2061-2073. https://doi.org/10.1007/s00603-013-0535-z

Johansson F, Stille H (2014) A conceptual model for the peak shear strength of fresh and unweathered rock joints. Int J Rock Mech Min Sci 69:31-38. https://doi.org/10.1016/j.ijrmms.2014.03.005

Ladanyi B, Archambault G (1969) Simulation of shear behavior of a jointed rock mass. Ussymp Rock Mech 20:2359-2365. https://doi.org/10.1161/01.ATV.20.11.2359

Li YR, Huang RQ (2015) Relationship between joint roughness coefficient and fractal dimension of rock fracture surfaces. Int J Rock Mech Min Sci 75:15-22. https://doi.org/10.1016/j.ijrmms.2015.01.007

Li YR, Zhang YB (2015) Quantitative estimation of joint roughness coefficient using statistical parameters. Int J Rock Mech Min Sci 77:27-35. https://doi.org/10.1016/j.ijrmms.2015.03.016

Liu QS, Tian YC, Ji PQ et al (2017) Updates to JRC-JCS model for estimating the peak shear strength of rock joints based on quantified surface description. Eng Geol 228:282-300. https://doi.org/10.1016/j.enggeo. 2017.08.020

Liu QS, Tian YC, Ji PQ et al (2018) Experimental investigation of the peak shear strength criterion based on three-dimensional surface description. Rock Mech Rock Eng 51:1005-1025. https://doi.org/10.1007/s00603-017-1390-0

Ma H, Tian YC, Liu QS et al (2020) Experimental study on the influence of height and dip angle of asperity on the mechanical properties of rock joints. Bull Eng Geol Environ. https://doi.org/10.1007/s10064-020-01904-w.

Nasseri MHB, Grasselli G, Mohanty B (2010) Fracture toughness and fracture roughness in anisotropic granitic rocks. Rock Mech Rock Eng 43:403-415. https://doi.org/10.1007/s00603-009-0071-z

Patton FD (1966) Multiple modes of shear failure in rock. 1st congress of International Society of Rock Mechanics. Lisbon 1:509-513.

Schneider H (1976) The friction and deformation behavior of rock joints. Rock Mech 8:169-184. https://doi.org/10.1007/BF01239813 
Tang ZC, Huang RQ, Liu QS et al (2016) Effects of contact state on the shear behavior of artificial rock joint. Bull Eng Geol Environ 75:761-769. https://doi.org/10.1007/s10064-015-0776-Z

Tatone BSA, Grasselli G (2009) A method to evaluate the three-dimensional roughness of fracture surfaces in brittle geomaterials. Rev Sci Instrum 80:125110. https://doi.org/10.1063/1.3266964

Tatone BSA, Grasselli G (2010) A new 2D discontinuity roughness parameter and its correlation with JRC. Int J Rock Mech Min Sci 47:1391-1400. https://doi.org/10.1016/j.ijrmms.2010.06.006

Tian YC, Liu QS, Liu DF et al (2018) Updates to Grasselli's peak shear strength model. Rock Mech Rock Eng 51:2115-2133. https://doi.org/10.1007/s00603-018-1469-2

Xia CC, Tang ZC, Xiao WM et al (2014) New peak shear strength criterion of rock joints based on quantified surface description. Rock Mech Rock Eng 47:387-400. https://doi.org/10.1007/s00603-013-0395-6

Yang J, Rong G, Cheng L et al (2015) Experimental study of peak shear strength of rock joints. Chin J Rock Mech Eng 34:884-894. https://doi.org/10.13722/j.cnki.jrme.2014.1096

Yang J, Rong G, Hou D et al (2016) Experimental study on peak shear strength criterion for rock joints. Rock Mech Rock Eng 49:821-835. https://doi.org/10.1007/s00603-015-0791-1

Yang ZY, Lo SC, Di CC (2001) Reassessing the joint roughness coefficient (JRC) estimation using Z $Z_{2}$. Rock Mech Rock Eng 34:243-251. https://doi.org/10.1007/s006030170012

Zhang XB, Jiang QH, Chen N et al (2016) Laboratory investigation on shear behavior of rock joints and a new peak shear strength criterion. Rock Mech Rock Eng 49:3495-3512.https://doi.org/10.1007/s00603-016-1012-2

Zheng BW, Qi SW (2016) A new index to describe joint roughness coefficient (JRC) under cyclic shear. Eng Geol 212:72-85. https://doi.org/10.1016/j.enggeo.2016.07.017 


\section{Figures}

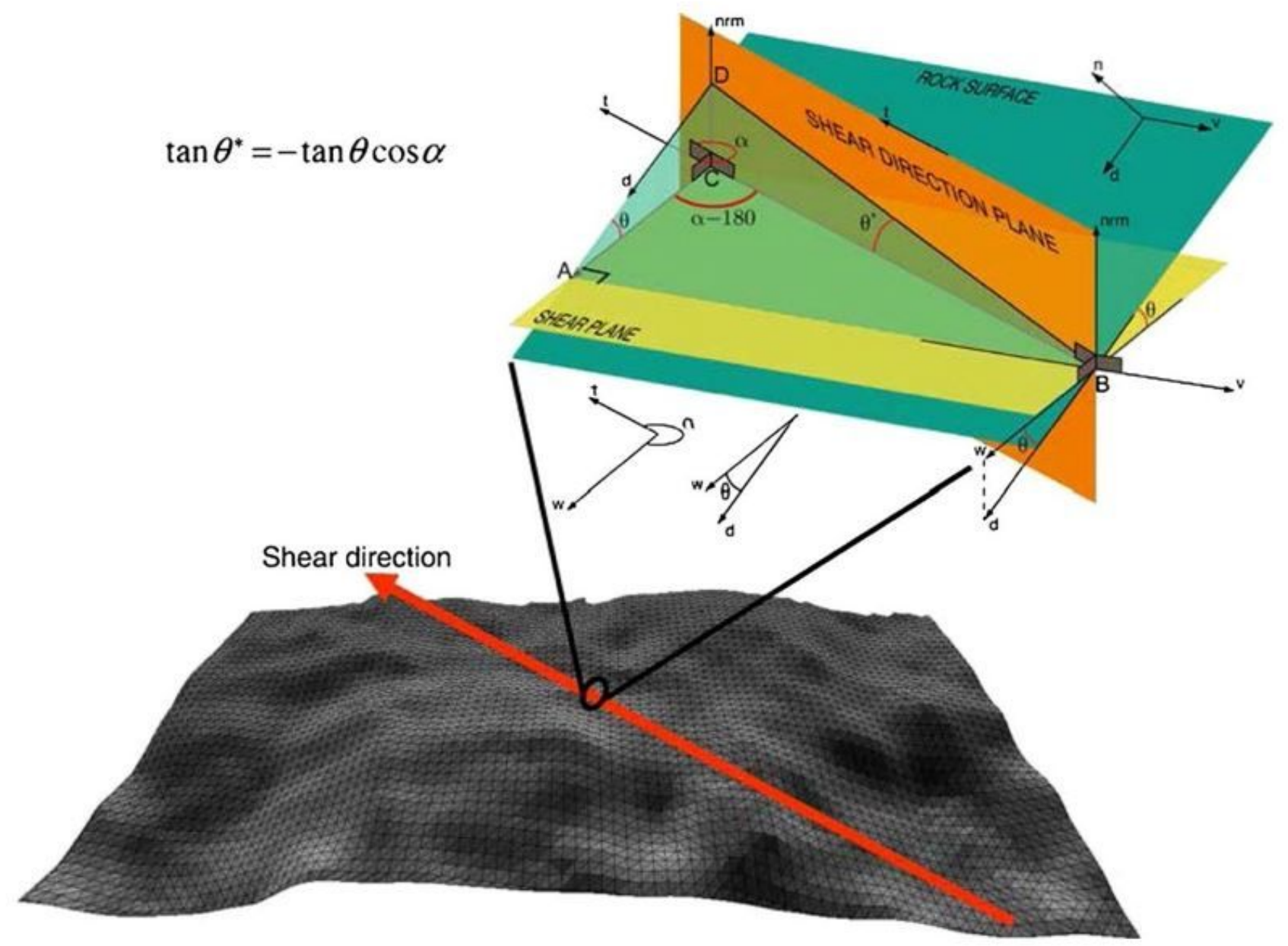

Figure 1

Geometrical identification of the apparent dip angle $\theta^{*}$, measured along the shear direction (Grasselli 2002; Nasseri 2010; Xia 2014) 


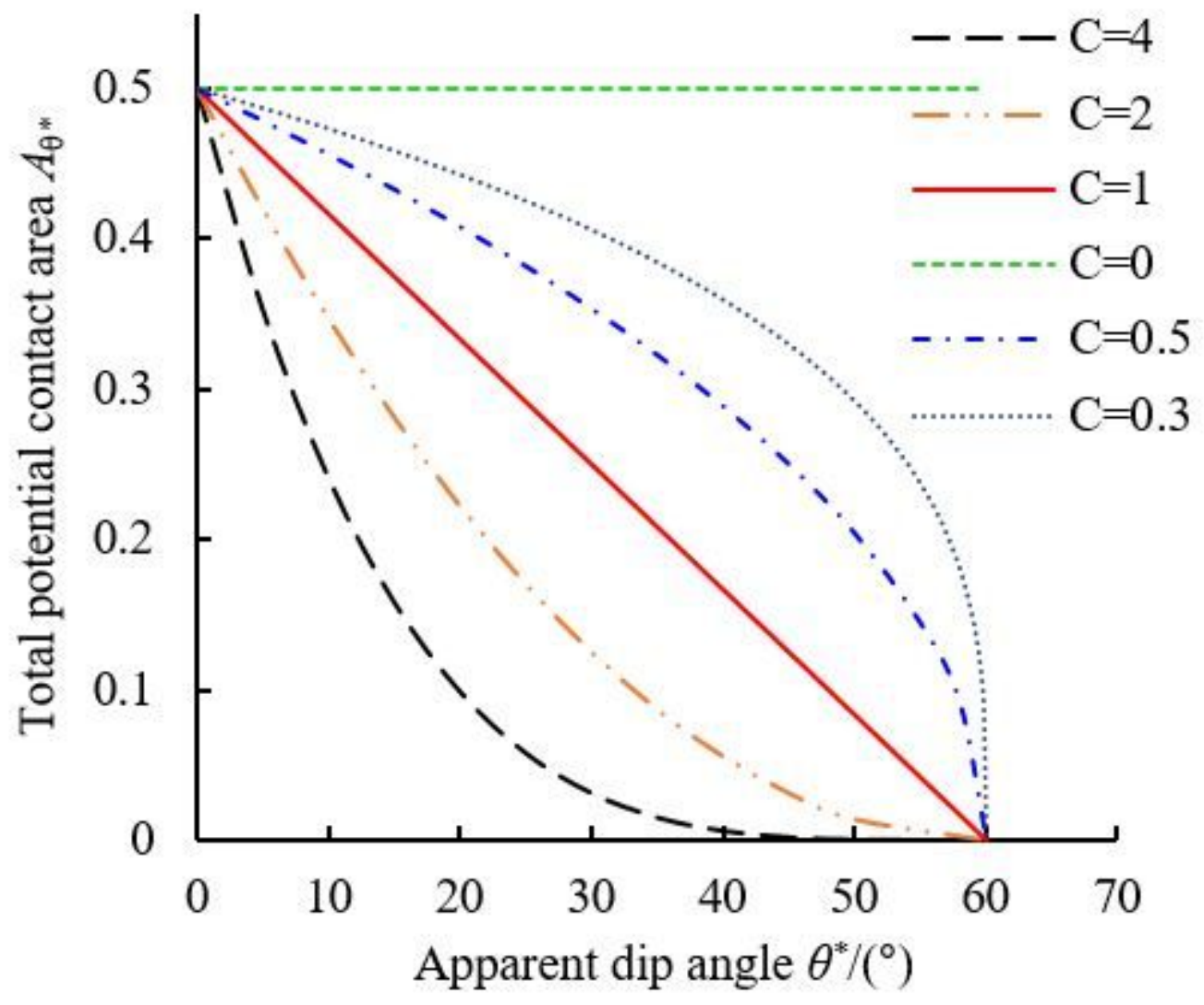

Figure 2

Evolution of contact area with apparent dip angle and roughness parameter $\mathrm{C}$ 

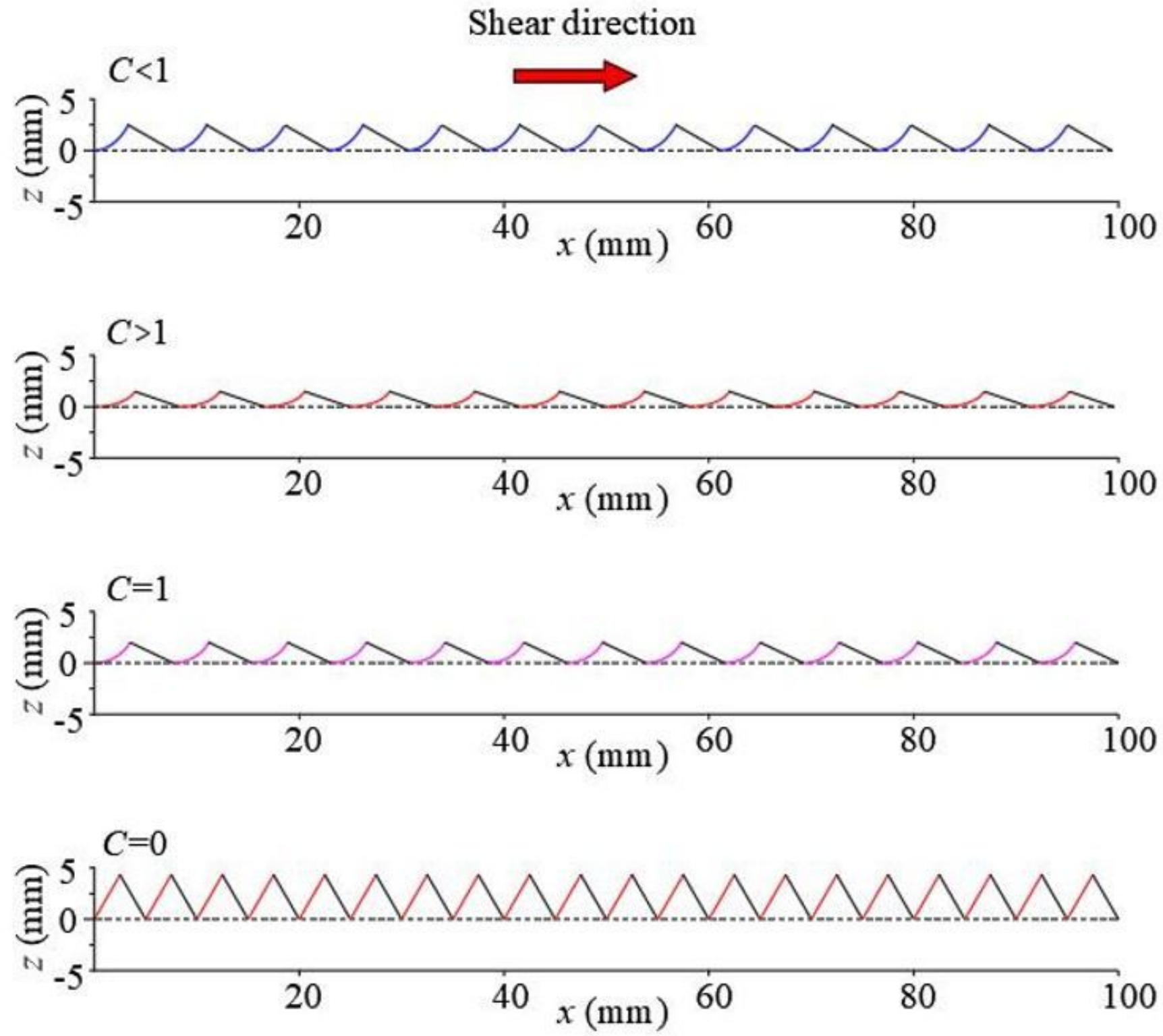

Figure 3

Two-dimensional average morphology of joints under different $\mathrm{C}$ 


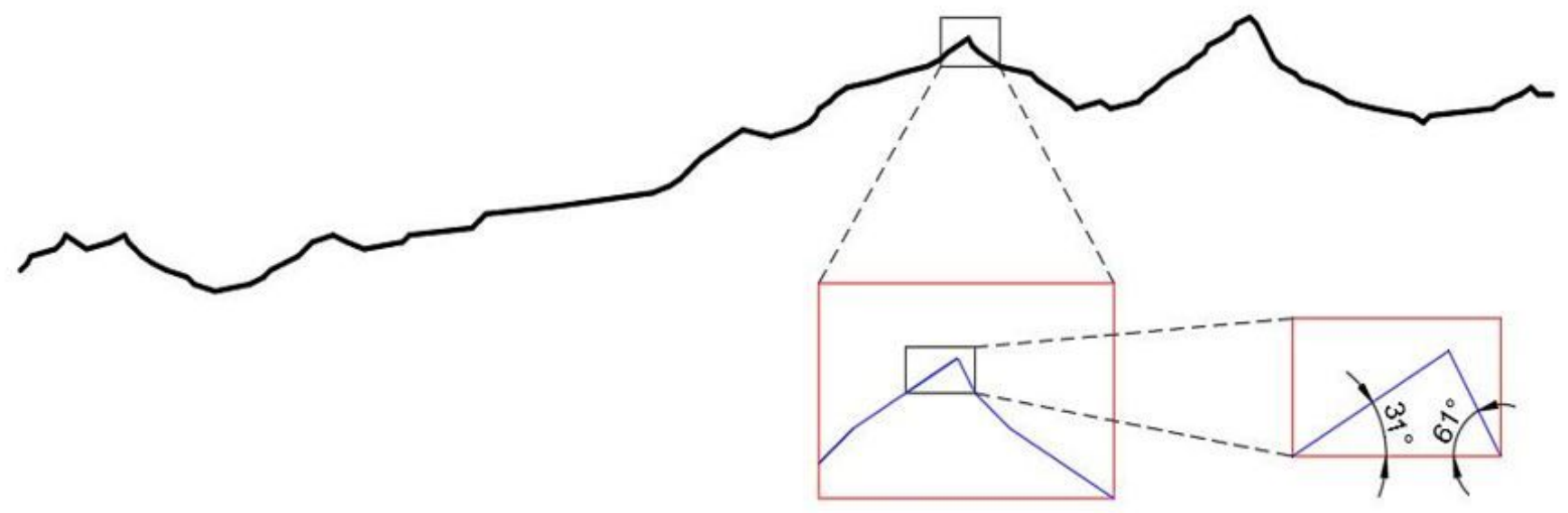

Figure 4

Geometrical properties of two-dimensional morphology in the forward and reverse of shear direction
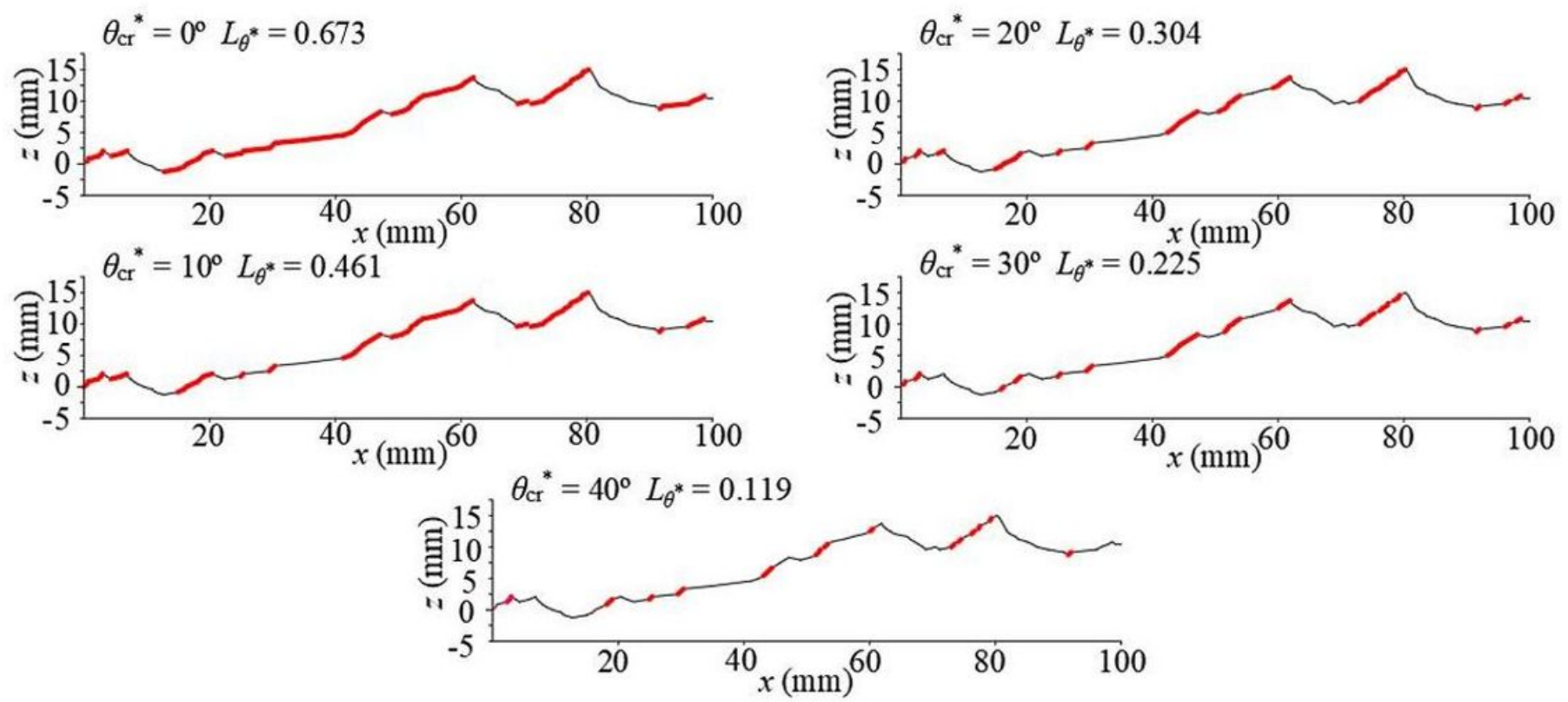

Figure 5

Evolution of normalized length with threshold apparent dip angle $\theta \mathrm{cr}^{\star}$ 


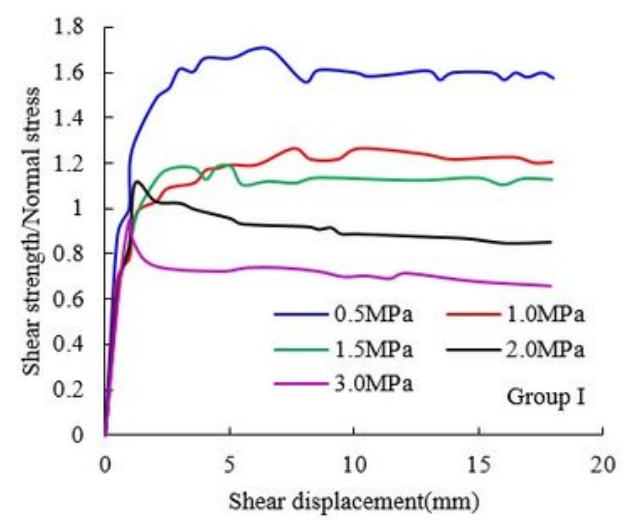

(a) Shear strength/normal stress versus shear displacement for Group I

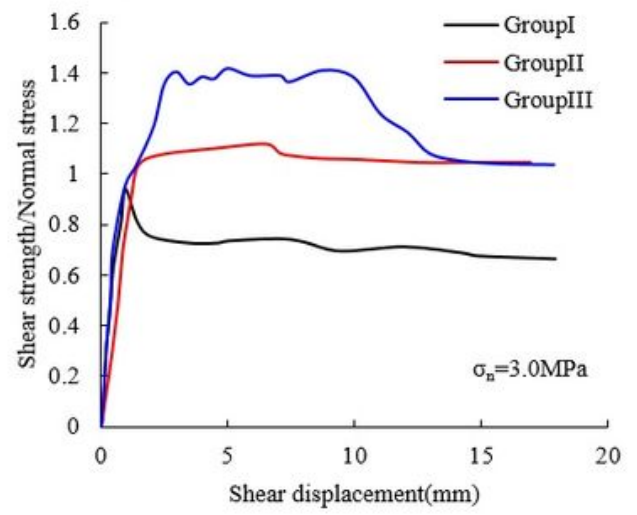

(b) Shear strength/normal stress versus shear displacement with different roughness under $\sigma_{\mathrm{n}}=3.0 \mathrm{MPa}$

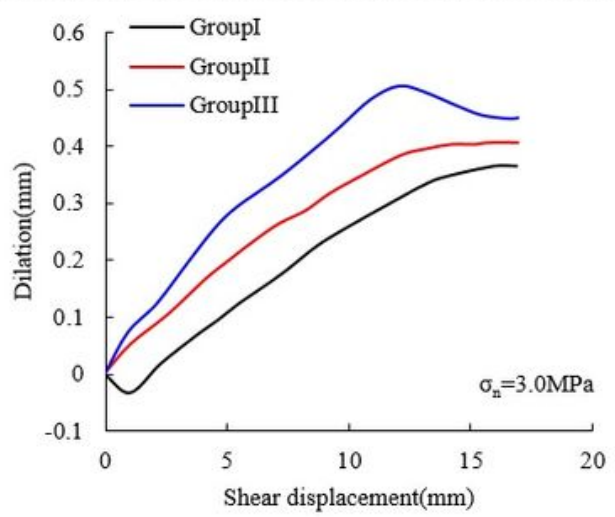

(c) Dilation versus shear displacement with different roughness under $\sigma_{\mathrm{n}}=3.0 \mathrm{MPa}$

\section{Figure 6}

Typical curves of the direct shear tests (Xia 2014) 


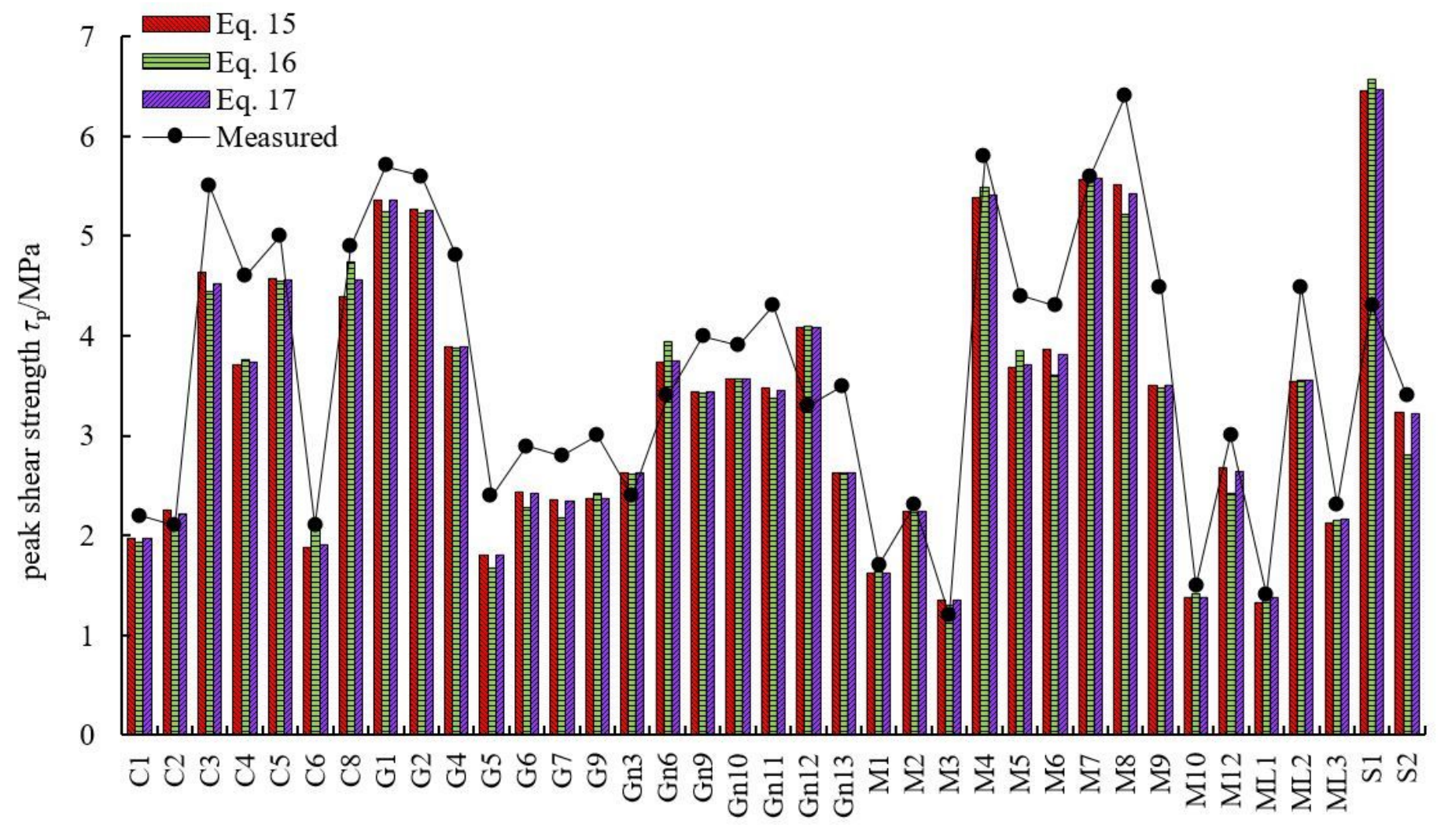

sample number

Figure 7

Comparison of measured values and calculated values based on Grasselli's test data 


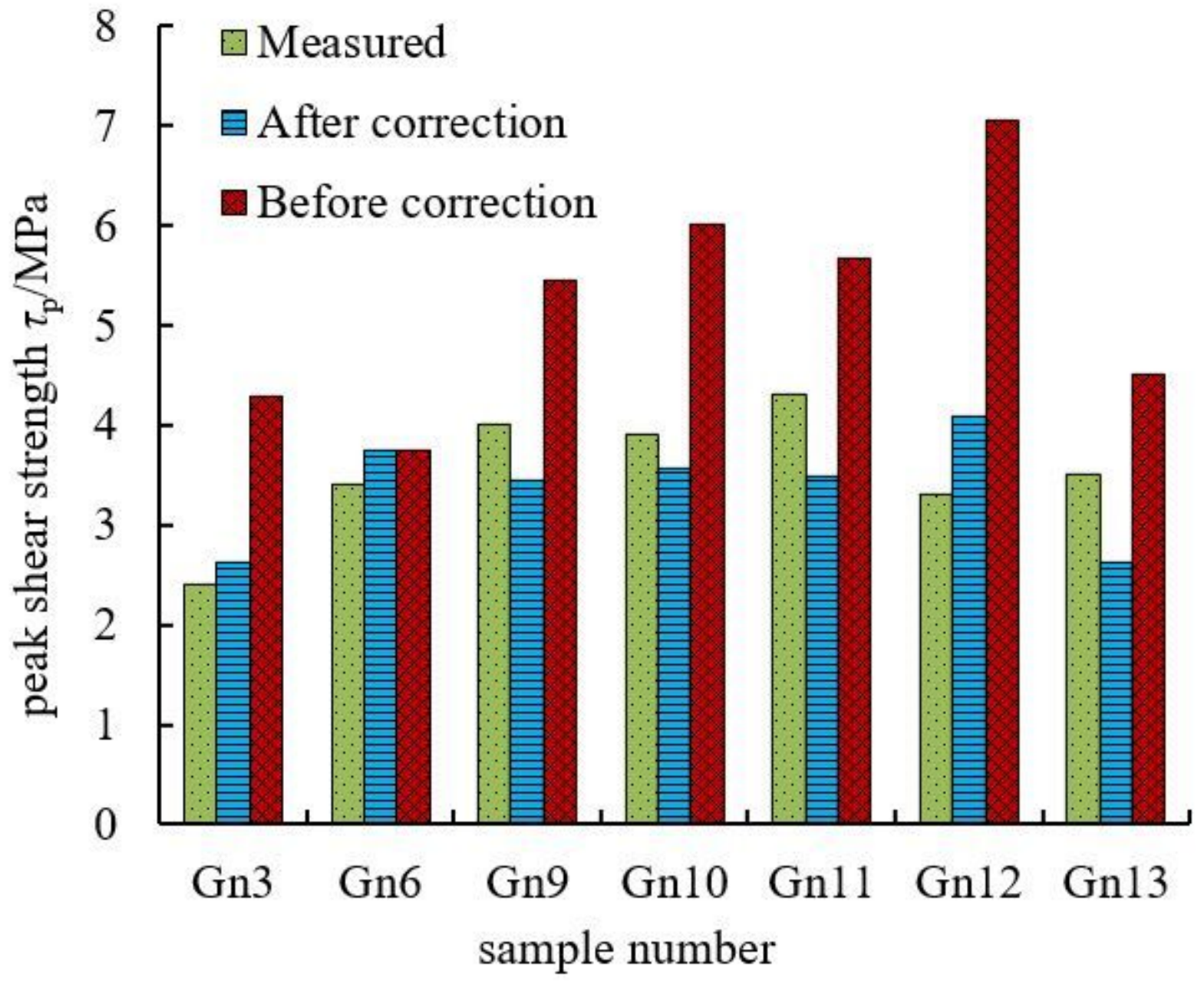

Figure 8

Comparison of measured values and calculations before and after initial dilation correction 